CENTRE POUR LA RECHERCHE ECONOMIQUE ET SES APPLICATIONS

Document de travail (Docweb) no 1516

\title{
Implementing Monetary Policy in a Fragmented Monetary Union
}

\author{
Miklos Vari
}

Doctoral meetings of the Research in International Economics and Finance (RIEF) network Cepremap Best Papers Prize 2015 


\title{
Implementing Monetary Policy in a Fragmented Monetary Union
}

\begin{abstract}
This paper shows how interbank market fragmentation disrupts monetary policy implementation. Fragmentation is defined as the situation where some banks are cut from the interbank loan market. The paper introduces fragmentation into an otherwise standard theoretical model of monetary policy implementation, where profit maximizing banks, subject to reserve requirements, borrow and deposit funds at the central bank. In the presence of fragmentation, excess liquidity arises endogenously and the interbank rate declines below the central bank main rate. The interbank rate is then unstable. Using data on cross-border financial flows and monetary policy operations, this paper shows that this mechanism has been at work in the euro area since 2008. The model is suitable to analyze conventional and unconventional monetary policy measures in the euro area as well as in other currency areas.
\end{abstract}

Keywords: Fragmentation, Excess liquidity, interbank market, TARGET2 imbalances

JEL Classification: E52, E58, E43, E42, F32, F36

\section{Mise en œuvre la de politique monétaire dans une union monétaire fragmentée}

Résumé : Cet article montre comment la fragmentation du marché interbancaire - définie comme une situation où certaines banques sont exclues du marché des prêts interbancaires - perturbe la mise en œuvre de la politique monétaire. La fragmentation est introduite dans un modèle standard de mise en œuvre de la politique monétaire, où des banques qui maximisent leurs profits sous contrainte de réserves obligatoires, empruntent et déposent des fonds à la banque centrale. En présence de fragmentation, la liquidité excédentaire apparaît de manière endogène et le taux interbancaire décline sous le taux principal de la banque centrale. Le taux interbancaire devient donc instable. L'article documente que ce mécanisme est à l'œuvre dans la zone euro depuis 2008 en utilisant des données sur les flux financiers transfrontaliers et les opérations de politique monétaire. Le modèle est également adapté à l'analyse de mesures conventionnelles et nonconventionnelles de politique monétaires en zone euro et dans d'autres pays.

Mots-clefs : Fragmentation, liquidité excédentaire, marché interbancaire, déséquilibres TARGET2

Classification JEL : E52, E58, E43, E42, F32, F36

1 Paris School of Economics and Banque de France. E-mail: Miklos.Vari@banque-france.fr. I would like to thank Jean Imbs, Jean-Edouard Colliard, Morten Bech, Julia Schmidt, Daniele Siena, Philippe Martin, Harald Uhlig, Benjamin Sahel, Gilles Saint-Paul, Ulrich Bindseil, Yannick Kalantzis, Eric Monnet, Thomas Werner, participants at the 2014 ECB Workshop "Structural changes in money markets: Implications for monetary policy implementation", participants at the Royal Economic Society junior symposium 2015, participants at seminars in Banque de France and the Paris School of Economics for their comments. All remaining errors are mine. The views expressed in this paper are mine and do not necessarily reflect those of the Banque de France or of the Eurosystem. 


\section{Introduction}

Since 2008, the liquidity provided by central banks in many countries has increased dramatically, but for different reasons. In the United-States, the increase of liquidity, in the form of bank reserves at the central bank (also called central bank money), follows from assets purchases by the Fed. By contrast, in the Euro-Area, during most of the crisis, the amount of loans demanded by banks to the Eurosystem has driven the changes in the amount of liquidity. ${ }^{1}$ This difference is visible from the balance sheets of central banks, as shown on Figure 1 and Figure 2. The volatility of the Eurosystem's balance sheet compared to the Fed's suggests that the increase in liquidity was the result of policy makers' decision in the US while it was dictated by the demand of banks for liquidity in the Euro-Area.

Figure 1: Simplified Fed balance sheet Figure 2: Simplified Eurosystem balance (USD, trillion) sheet (EUR, trillion)

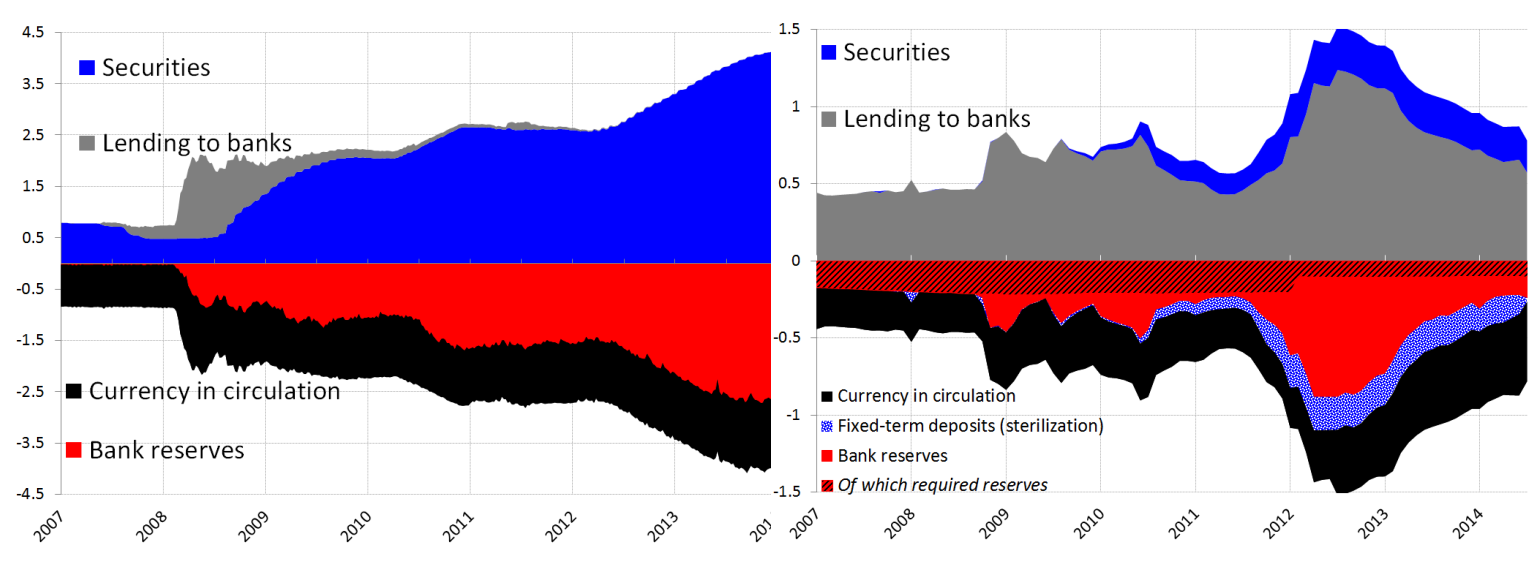

Note: Assets of the central bank are counted as positive and liabilities as negative.

Source: Federal Reserve Bank of New of New York and ECB.

The fluctuations of liquidity in the Euro-Area have directly impacted the short term interbank rate and caused it to move also in a seemingly unpredictable manner. Figure 3 shows the evolution of the interbank rate with respect to the "corridor". 2 Contrary to the pre-crisis period where the interbank rate was tracking closely the central bank main interest rate, since 2008 it has deviated substantially from it. The interbank rate being a key transmission channel of central banks's decisions, such fluctuations represent a significant disruption of monetary

\footnotetext{
${ }^{1}$ As an accounting identity, Euros lent by the Eurosystem to banks end up on the accounts banks hold with the Eurosystem or in the hands of the public in the form of currency. Absent changes in the demand for currency from the public, more Euros lent translate into more bank reserves.

${ }^{2}$ The corridor is the interval between the rate of the marginal lending facility (at which banks can borrow overnight from the central bank) and the rate of the deposit facility (at which banks can deposit funds). These two rates provide a ceiling and a floor to the overnight interbank rate, the European OverNight Index Average ("EONIA").
} 
policy implementation. These fluctuations have impacted the rest of the yield curve (Figure 6 in appendix) and probably the real economy.

Figure 3: The ECB key interest rates and the interbank rate since 2005

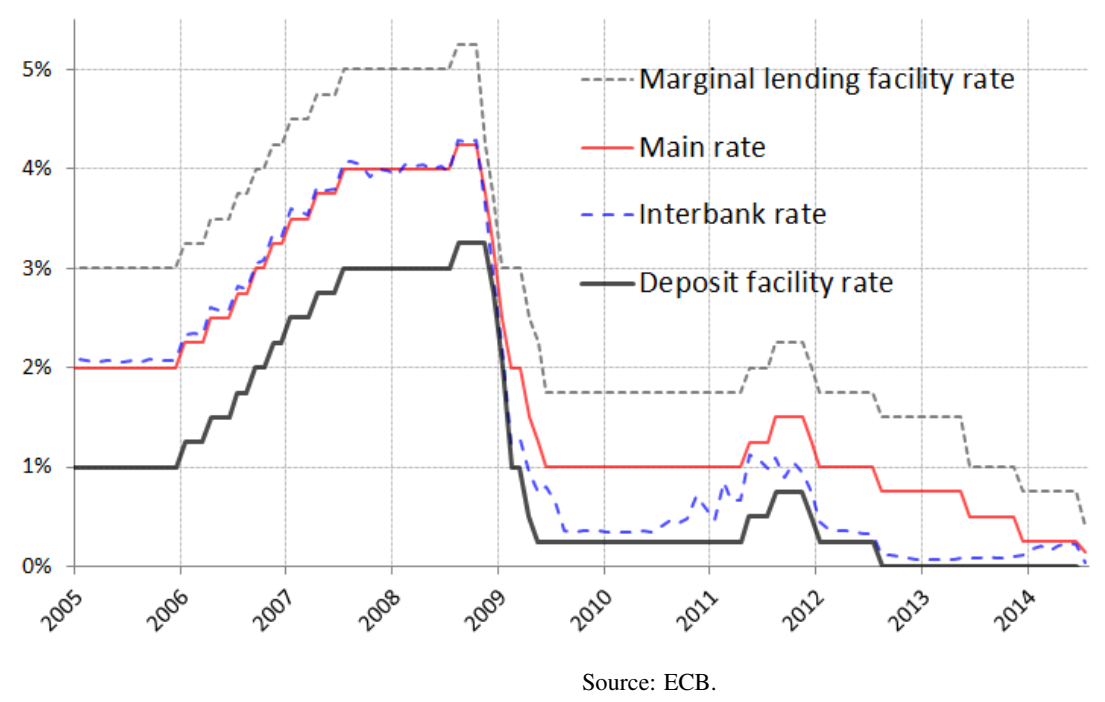

The goal of this paper is to explain the joint dynamics of liquidity and the interbank rate in the Euro-Area since October 2008. It shows that in order to understand such dynamics, it is crucial to take into account the fragmentation of the Euro-Area banking system. Therefore, the paper introduces fragmentation into an otherwise standard model of monetary policy implementation. ${ }^{3}$ Fragmentation is defined as the situation where some banks ("peripheral" banks) are cut from the interbank market where the other banks ("core" banks) transact.

In the model, peripheral banks are cut from the interbank market because it is perceived risky to lend to them. This higher risk is due to: the strained fiscal situation of the government, the risk of exiting the monetary union or the adverse macroeconomic situation of the countries of origin of these banks. It is assumed that fragmentation arises when peripheral banks are in a net debtor position toward core banks, reflecting macroeconomic imbalances and in particular the net liability position of peripheral countries toward core countries. When peripheral banks lose access to the interbank market, they have no other choice but to borrow from the central bank to repay the loans from core banks, which are not rolled over. This is equivalent to a deposit flight. Hence, in times of fragmentation, peripheral banks will have to borrow more than in normal times from the central bank. Core banks will not borrow at all from the central bank and will have a surplus of liquidity. The model predicts that on aggregate, there will

\footnotetext{
${ }^{3}$ Traditional models of monetary policy implementation follow from Poole (1968). Contributions to this literature include notably Nautz (1998), Bindseil et al. (2004), Whitesell (2006) and Bech and Keister (2013). The framework presented in this paper is closest to Bech and Keister (2013).
} 
be more liquidity than in normal times because the increase in the demand for liquidity from peripheral banks is not matched by a decrease from core banks, as they do not borrow anything. Hence, excess liquidity arises endogenously in the model. Due to this surplus, the interbank rate (which reflects only the price of transactions between core banks) is lower than the central bank main rate. In fine, the amount of liquidity and the interbank interest rate will fluctuate according to the size of the deposit flight, which is out of the control of the central bank. This explains the rise in excess liquidity, the decline in the interbank rate and the so-called “TARGET2 imbalances" observed in the Euro-Area since 2008.

The model shows that the explanation according to which banks in the Euro-Area are willing to accumulate precautionary reserves at the central bank can account for the increase in the amount of liquidity borrowed from the central bank but it cannot replicate the decrease in the interbank rate. ${ }^{4}$ Ceteris paribus, an increase in demand cannot generate a fall in prices.

Empirical evidence provided in this paper strongly supports the theoretical mechanism. Using data on cross-border financial flows and central bank liquidity, the econometric analysis shows that, indeed, the deposit flight (a by-product of fragmentation) has driven liquidity movements since 2008. Then, it is shown that equilibrium conditions derived in the theoretical section, combined with data on central bank liquidity, are able to match closely the observed movements in the interbank rate.

The paper derives several policy implications. First, by providing large amounts of liquidity at favorable conditions from the start of the crisis, the Eurosystem avoided further divergence in financing conditions across the Euro-Area. However, by doing so it has also hampered the functioning of the interbank market. The full recovery of the interbank market and the reduction of TARGET2 imbalances therefore will require the Eurosystem to provide liquidity under stricter conditions. Second, there are ways to stabilize the interbank rate even when the banking system is fragmented. The central bank can purchase a large amount of assets to increase the reserves of core banks, pushing down the interbank rate and anchoring it at the deposit facility rate. An alternative solution to stabilize the interbank rate would be to absorb excess liquidity. The model shows that in case of fragmentation, contrary to normal times, the central bank can withdraw liquidity from the banking system, even if banks can borrow as much as they wish from the central bank.

\footnotetext{
${ }^{4}$ Commentators and the financial press often argue that the amount of liquidity in the Euro-Area has increased because of liquidity hoarding behavior of banks. See for instance Reuters (2012) or The Wall Street Journal (2013).
} 
The rest of the paper is organized as follows. Section 2 presents the theoretical model. Section 3 discusses policy implications. Section 4 presents empirical evidence and section 5 concludes.

\section{The model}

This section develops the theoretical model that allows to understand fluctuations of liquidity and interbank rates.

First, a traditional model of monetary policy implementation is adapted to the Euro-Area. It is shown that this type of models is a useful workhorse but cannot explain why there has been an increase of liquidity or a decline of the interbank rate. Second, it is shown that traditional explanations for the increase of liquidity such as liquidity hoarding by banks, liquidity regulation or the so called "fixed-rate full allotment" cannot replicate the decline of the interbank rate. The main theoretical contribution of the paper lies in the third subsection where fragmentation is introduced and shown to explain convincingly fluctuations of liquidity and of the interbank rate.

\subsection{Monetary policy implementation in a well integrated banking system}

The model draws from Bech and Keister (2013) which is in the tradition of models of Poole (1968). These models show how banks subject to minimum reserve requirements maximize their expected profits by choosing the amount of interbank loans they make, depending on how much liquidity is created by the central bank. Contrary to most models of monetary policy implementation where the central bank injects liquidity by buying assets from banks (as done in the US), the model presented below features a central bank that makes loans to banks (as done in the Euro-Area).

The timing of the model is the following: first, the central bank conducts its refinancing operation, by which it injects liquidity (bank reserves) in the banking system. Second, the trading session for interbank loans occurs. Third, once the interbank market is closed, banks experience a "late" deposit shock. Fourth, banks go to the central bank standing facilities. These standing facilities are either the marginal lending facility (the US equivalent is the "Discount Window") at which the banks can borrow overnight unlimited amount of funds at a penalty rate, or the 
deposit facility at which banks can deposit funds on an interest bearing account. ${ }^{5}$ Indeed, in the Euro-Area, standing facilities are made accessible only when the payment system closes and all interbank transactions have been processed (at 18:30). Since, an interbank loan takes some time to be set up, no interbank loans are initiated after 17:00. Any unexpected payment arising between 17:00 and 18:30 can only be compensated by going to the Eurosystem standing facilities (see Bindseil et al. (2004)).

Diagram 1: Timing of the model

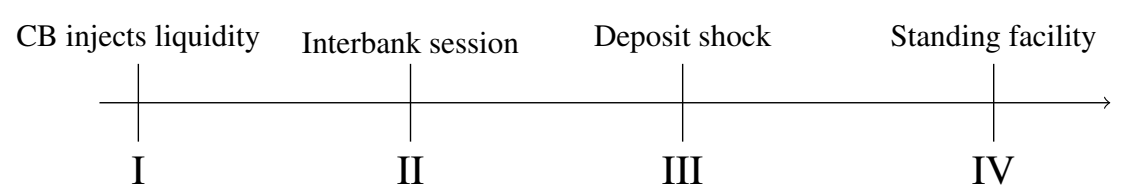

The game is now solved backward, period per period.

\subsubsection{Recourse to central bank standing facilities}

The central bank marginal lending facility refers to a facility that is accessible after the interbank session is closed to borrow overnight without limit from the central bank. During this phase the central bank is passive and the banks take the decision to access or not the facility depending on its needs. The funds borrowed at the standing facility are meant to address liquidity shocks and cannot be lent to other banks. The funds are credited to the account of the bank that access the facility after the interbank session and taken out before the next session starts.

In this model, the central bank imposes minimum reserve requirements to its banks, as is the case for instance in the Euro-Area, in the US and in over $90 \%$ of central banks in the world (Gray (2011)). These reserves requirements take the form of the following constrain for bank "i":

$$
R^{i}+B^{i}-\epsilon^{i}+X^{i} \geq K^{i}
$$

where $K^{i}$ is set by the central bank and corresponds to the amount of liquidity that bank "i" must

\footnotetext{
${ }^{5}$ Banks borrowing from the central bank have to provide adequate collateral against the funds, at least in the case of major central banks (Cheun et al. (2009)). In the present paper, it is assumed that banks always have sufficient collateral to accommodate their borrowing needs.
} 
keep on its current account at the central bank. ${ }^{6} R^{i}$ is the amount of reserves held by bank "i" at the central bank at the end of period I (so it excludes borrowing from the central bank standing facility, interbank borrowings or any deposit shock). $B^{i}$ are interbank borrowings (negative values are interbank loans). $\epsilon^{i}$ is a deposit shock of the bank. $X^{i}$ are overnight borrowing from the central bank' standing facility. This facility is automatically activated by the central bank, whenever (1) is not respected. Therefore:

$$
X^{i}=\max \left\{K^{i}-\left(R^{i}+B^{i}-\epsilon^{i}\right) ; 0\right\}
$$

It means that banks have to go to the central bank in case a reserve deficiency appears after the interbank market has closed (when they cannot change $B^{i}$ ).

Funds deposited at the central bank to meet minimum reserve requirements are not remunerated, while funds deposited at the central bank in excess of reserve requirements (so called "excess reserves") are remunerated at $r_{r}{ }^{7} r_{r}$ is the interest on excess reserves, also called the deposit facility rate.

\subsubsection{Deposit shock}

$\epsilon^{i}$ is some random deposit shock that occurs after the interbank market has closed $\left(\epsilon^{i}>0\right.$ is an unexpected net withdrawal of funds from bank " $\mathrm{i}$ " and $\epsilon^{i}<0$ an unexpected net inflow of funds). These shocks on the liquidity positions of banks can push them to use the central bank standing facilities, to avoid a minimum reserves deficiency. By an abuse of notation $\epsilon^{i}$ denotes both the random variable and its realization. $g($.$) is the density function of the random variable.$ $\epsilon^{i}$,s are independently distributed across banks and $E\left(\epsilon^{i}\right)=0$. Further, $G($.$) , the cumulative$ distribution function of $\epsilon^{i}$ is symmetric around $0\left(G\left(E\left(\epsilon^{i}\right)\right)=G(0)=0.5\right) .^{8}$

\footnotetext{
${ }^{6}$ Reserve requirements are usually set by the central bank to stabilize the demand of liquidity from banks and by the same token market rates (see Ennis and Keister (2008)). To do so central banks allow commercial banks to average the fulfillment of reserve requirements over some period. In this model, $K^{i}$ is interpreted as the reserve requirements over this period i.e. the bank within the game has to meet (1) at all time, not on average. The same interpretation is made in Bech and Keister (2013).

${ }^{7}$ In reality, central banks tend to remunerate minimum reserves (Gray (2011)). It does not change anything in this model to assume that minimum reserves are remunerated or not as long as one assumes a large financial penalty in case of non-compliance with minimum reserve requirements. To see when this has an impact see Whitesell (2006).

${ }^{8}$ Economically, these shocks can be interpreted as all liquidity shocks that hit banks and that cannot be mitigated by borrowing/lending on the interbank market. Depositors withdrawing more/less from cash machines than expected produce the same kind of shocks, as the cash withdrawn from one bank does not go back immediately to the banking system. The fact that $G\left(E\left(\epsilon^{i}\right)\right)=G(0)=0.5$ just means that the forecast of banks regarding this type of liquidity needs is unbiased. In practice, forecasts of total cash to be withdrawn are published by the Eurosystem every week. This forecast is unbiased (Gonzalez-Paramo (2007)).
} 
$\hat{\epsilon}^{i}$ is defined such that for given $R^{i}, B^{i}$ and $K^{i}$ :

$\epsilon^{i}>\hat{\epsilon}^{i} \Rightarrow X^{i}>0 . \hat{\epsilon}^{i}$ is a threshold, which defines the amount of deposit withdrawals above which bank "i" has to borrow from the central bank standing facility $\left(X^{i}>0\right)$. Therefore:

$$
\hat{\epsilon}^{i}=R^{i}+B^{i}-K^{i}
$$

$R \equiv \int_{0}^{1} R^{i} d i$ is the total amount of reserves in the banking system excluding deposit shocks and the amount borrowed via the marginal lending facility, $X \equiv \int_{0}^{1} X^{i}$. It is made of liquidity created by the loans of the central bank to banks $(M)$, the central bank outright transactions $(O)$, such as asset purchases $(O>0)$ or asset sales $(O<0)$ minus the amount currency in circulation $(C>0)$. It follows that by identity:

$$
R=M+O-C
$$

\subsubsection{The interbank market}

The profit function of bank " $\mathrm{i}$ " writes:

$$
\Pi^{i}=-r_{X} X^{i}-r_{B} B^{i}-r_{D}\left(D^{i}-\epsilon^{i}\right)-r_{M} M^{i}+r_{r}\left(R^{i}+B^{i}-\epsilon^{i}+X^{i}-K^{i}\right)
$$

Reserves held at the end of the day (end of period IV) in excess of minimum reserves (excess reserves) yield $r_{r}$ while minimum reserves yield some rate that is assumed to be zero to avoid cumbersome notations. Deposits (D) and the overnight central bank borrowings (X) cost to the bank interests $r_{D}$ and $r_{X}$ to the bank respectively. $r_{M}$ is the interest paid on money borrowed from the central bank refinancing operation $\left(M^{i}\right)$.

This profit function is very general. One could easily add additional items such as loans to non-financial corporations and households. Taking into account that recipients of a bank loans deposit the funds with a bank or convert them into currency (which is modeled here), means that adding bank loans does not add anything to the model at this point (see appendix II). One can modify the profit function to adapt it to the different central bank framework. For instance, in the US, $M=0$ and monetary policy is implemented mainly through outright operations or temporary changes in the stock of assets held by the central bank (change in $O$ ). In the Eurosystem, $M>0$. 
Rearranging, substituting (2) into (5) and taking expectations yields:

$$
\begin{aligned}
E\left[\Pi^{i}\right]=-r_{B} B^{i}-r_{D} D^{i}-r_{M} M^{i}+r_{r}\left(R^{i}+B^{i}-\right. & \left.K^{i}\right) \\
& -\left(r_{X}-r_{r}\right) E\left[\max \left\{K^{i}-\left(R^{i}+B^{i}-\epsilon^{i}\right) ; 0\right\}\right]
\end{aligned}
$$

$g($.$) is the density function of \epsilon^{i}$ (it is the same for all $\epsilon^{i}$ 's) and $\hat{\epsilon}^{i}$ is the threshold above which a deposit shock is large enough to force the bank to borrow from the central bank standing facility. Therefore:

$$
\begin{aligned}
E\left[\Pi^{i}\right]=-r_{B} B^{i}-r_{D} D^{i}-r_{M} M^{i}+r_{r}\left(R^{i}+B^{i}\right. & \left.-K^{i}\right) \\
& -\left(r_{X}-r_{r}\right) \int_{\hat{\epsilon}^{i}}^{\infty} g\left(\epsilon^{i}\right)\left(K^{i}-\left(R^{i}+B^{i}-\epsilon^{i}\right)\right) \mathrm{d} \epsilon^{i}
\end{aligned}
$$

Bank " $\mathrm{i}$ " chooses $B^{i}$ to maximize its profit. If $\mathrm{G}($.$) is the strictly increasing cumulative$ distribution function of $\epsilon^{i}$ s, it means that:

$$
\begin{aligned}
& \frac{\partial E\left[\Pi^{i}\right]}{\partial B^{i}}=0 \\
& \Rightarrow r_{B}=r_{r} G\left(\hat{\epsilon}^{i}\right)+r_{X}\left(1-G\left(\hat{\epsilon}^{i}\right)\right)
\end{aligned}
$$

Banks will price their loans to other banks such that the revenue they receive from the transaction is equal to the expected value of not lending one more unit of fund. This expected value is equal to the probability of being long in cash $G\left(\hat{\epsilon}^{i}\right)$ times the remuneration of excess reserves $\left(r_{r}\right)$ plus the probability of being short in cash $1-G\left(\hat{\epsilon}^{i}\right)$ times the cost of borrowing from the central bank facility $\left(r_{X}\right)$.

Aggregating over the mass 1 of banks, it must be the case that:

$$
\int_{0}^{1} B^{i} d i=0
$$

Combining (3), (10) and (9) yields:

$$
r_{B}^{\star}=r_{r}+\left(r_{X}-r_{r}\right)(1-G(R-K))
$$

A starred variable denotes the market equilibrium level of this variable. $R \equiv \int_{0}^{1} R^{i} d i$ are the aggregate reserves and $K \equiv \int_{0}^{1} K^{i} d i$ is the aggregate reserve requirements of the banking system. 
$R-K$ is the amount of reserves in excess of minimum reserve requirements, also called the "excess liquidity". (11) shows that the level of excess liquidity directly impacts the level of the interbank rate. The higher (resp. lower) the level of excess liquidity the closer the interbank rate from the deposit (resp. marginal lending) facility rate.

\subsubsection{Central bank refinancing operation}

If the central bank controls $\mathrm{R}$, (11) shows that it can steer the interest rate in the interbank market toward a target $\left(r_{M}\right)$ using the rates on the deposit and the marginal lending facility, the reserve requirements and the total quantity of reserves in the banking system.

One can invert (11) to find:

$$
R^{c b}=K+G^{-1}\left(\frac{r_{X}-r_{M}}{r_{X}-r_{r}}\right)
$$

A variable with superscript " $c b$ " denotes the level of this variable that allows the central bank to reach its target $\left(r_{M}\right)$ for the interbank rate, also called the operational target of the central bank. ${ }^{9} r_{M}$ can be anywhere between the interest rates of the two standing facilities. For ease of presentation, it is assumed that it is at equal distance of the two rates, also called the middle of the "corridor". It does not change anything for the problem studied here that the target is closer from one facility rate, a situation referred as asymmetric corridor, studied in appendix III. Thus:

$$
r_{M}=\frac{r_{r}+r_{X}}{2}
$$

Equation (12) can be rewritten:

$$
R^{c b}=K+G^{-1}(1 / 2)
$$

Since $G(0)=0.5$, it follows that:

$$
R^{c b}=K
$$

\footnotetext{
${ }^{9}$ It is assumed that the central bank uses $R$ rather than $\mathrm{K}$ for its monetary policy. In reality, some central banks especially in emerging countries use the level of minimum reserves $K$ (Glocker and Towbin (2012)). Some developed countries exceptionally use reserve requirements to change the level of excess liquidity in the system but these are extremely rare changes, while R moves on a day-to-day basis. The Eurosystem lowered the level of reserves requirements in February 2012 (ECB (2011)).
} 
Using (4) above, yields:

$$
M^{c b}=K+C-O
$$

The central bank lends just enough liquidity for banks to be able to satisfy reserve requirements and the demand for currency in circulation, minus how much was already injected via outright purchase of assets. If:

$$
K>O-C
$$

it means that banks structurally need to borrow from the central bank in order to fulfill their reserve requirements. The Eurosystem does set minimum reserve requirements to make sure that banks need to borrow (ECB (2013a)). Therefore, in what follows it will be assumed that equation (17) holds.

It is crucial to note that this refinancing operation is a borrowing operation exclusively. This means that $M^{i} \geq 0$ for all i's.

This type of model was/is used by many central banks to implement their monetary policy. The framework is rather general and can be used for any central bank that targets the interbank interest rate. Before the crisis, major central banks such as the Eurosystem, the Fed, the Bank of Japan, the Bank of England, the Bank of Canada, the Reserve Bank of Australia and the Swiss National Bank were all targeting interbank rates (Borio and Nelson (2008) and Blenck et al. (2001)).

This model is a useful benchmark but a significant shortcoming is that it cannot explain excess reserves nor deviations of the interbank rate from the central bank main interest rate in the Euro-Area. The remainder of this theoretical section addresses this shortcoming.

\subsection{Conventional explanations of the increase in liquidity in the Euro-} Area

This subsection discusses several conventional explanations for the large excess liquidity observed in the Euro-Area during the last six years. It shows that none of them can account for the simultaneous decrease of the interbank rate (given that the central bank has not increased unilaterally the supply of liquidity as in the US). 


\subsubsection{Fixed-rate full allotment}

From its creation to October 2008 the Eurosystem was lending some fixed amount of liquidity to banks. In this case, the model developed in the previous subsection applies, and the central bank supplies an amount of loans equal to $M^{c b}$. However, since October 2008, the Eurosystem operates under a "fixed-rate full allotment" regime where banks individually ask for the quantity of liquidity they want (ECB (2008)) at fixed pre-announced rate (the ECB main interest rate). Hence, the money supply and the excess liquidity in the Euro-Area are endogenous to bank's behavior. How this changes the mechanics of monetary policy implementation is the focus of what follows.

Proposition 1: Under fixed-rate full allotment, in a perfectly integrated banking system, it must be the case that the interbank rate is equal to the policy rate $\left(r_{B}=r_{M}\right)$.

Proof: Note that it must be the case that: ${ }^{10}$

$$
r_{X}>r_{M}>r_{r}
$$

Assume that the expected interbank rate before the refinancing operation is conducted is strictly greater than the main central bank interest rate $\left(E\left[r_{B}\right]>r_{M}\right)$. Then, all banks borrow an infinite amount at the refinancing operation in order to lend it in the interbank market $R \rightarrow+\infty$. Using condition (11), this would mean that $r_{B}=r_{r}<r_{M} \Rightarrow r_{B} \neq E\left[r_{B}\right]$, this would not be an equilibrium. Therefore: $E\left[r_{B}\right] \leq r_{M}$. Assume $E\left[r_{B}\right]<r_{M}$, then no bank borrows at the refinancing operation $\left(M^{\star}=0\right)$ and given equation (17), there is not enough liquidity to fulfill reserve requirements. Then, banks need to go to the marginal lending facility and pay rate $r_{X}>r_{M}$. This means banks would be willing to transact at a rate somewhere between $r_{M}$ and $r_{X}$. This means $r_{B}>r_{M}$, which again is not an equilibrium. Therefore, for expectations to be consistent for any value of the parameters, it must be the case that $E\left[r_{B}\right]=r_{M}$. Bindseil (2014) obtains the same result in a different model.

Proposition 1 implies that $\int_{0}^{1} R^{i \star} d i \equiv R^{\star}=R^{c b}$ and $\int_{0}^{1} M^{i \star} d i \equiv M^{\star}=M^{c b}$. In other words,

\footnotetext{
${ }^{10}$ If $r_{M} \geq r_{X}$ banks would go to the overnight facility rather than the main operation to fulfill their reserve requirements. If $r_{M} \leq r_{X}$ they would borrow an infinite amount of reserves at the main rate and place the proceed at the central bank deposit facility. Therefore, for the main refinancing operation of the central bank to be used in finite amount it must be the case that: $r_{X}>r_{M}>r_{r}$.
} 
in a perfectly integrated banking system, the fixed-rate full allotment should result in the same quantity of liquidity and the same interbank rate as in the case where the central bank restricts the quantity of liquidity. ${ }^{11}$

\subsubsection{The impact of precautionary demand for liquidity and liquidity regulation}

If banks want to hold a liquidity buffer for precautionary motive (ECB (2014)) or if they use liquidity to fulfill liquidity regulation (ECB (2013b)), in this model this would translate into:

$$
\hat{\epsilon}^{i}=R^{i}+B^{i}-K^{i}-A^{i}
$$

where $A^{i} \geq 0$ is a reduced form way of capturing the fact that some banks anticipate that they will have to go to the marginal lending facility after a lower deposit shock than before because they might not be able to borrow in the interbank market as much as before. This is also true if banks ask for more liquidity because they legally have to hold cash on top of minimum reserve requirements or because they wish to appear cash-rich for the end-of-year reporting (see section 4). This has the same effect on banks' demand for liquidity as increasing minimum reserve requirements and would consequently increase the take up of banks at the central bank main refinancing operation, as shown on diagram 2 below.

Diagram 2: Demand for liquidity in times of stress $v s$ normal times

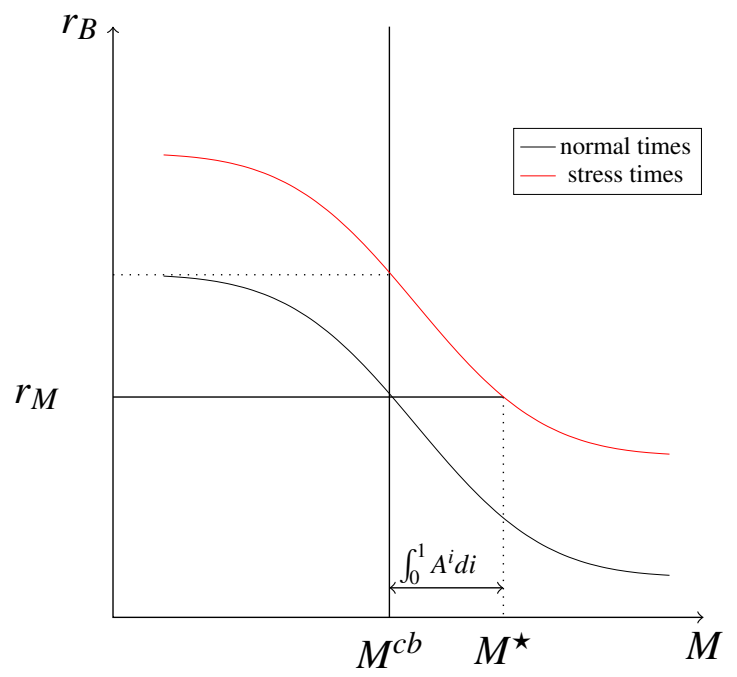

In a fixed-rate full allotment regime, liquidity would be higher (by $A \equiv \int_{0}^{1} A^{i} d i$ which would be the excess of liquidity) but the interbank rate should not change. Banks ask more to the cen-

\footnotetext{
${ }^{11}$ It should also be clear that negative interest rates do not change anything to the dynamic of the model. In reality, negative interest rates become problematic when the cost it imposes to banks is higher than the cost of storing banknotes. Then it becomes profitable to change excess liquidity into banknotes and excess liquidity disappears.
} 
tral bank but are not trading this liquidity at a lower rate than they borrowed it. If the central bank allots the same quantity of liquidity $\left(M^{c b}\right)$ as in normal times, it would push the interbank rate higher. ${ }^{12}$ The shape of the curves stems from the cumulative distribution function of a normal distribution.

Proposition 2: In a fixed-rate full allotment regime, ceteris paribus, if banks increase their demand for central bank financing for some precautionary motive or to fulfill a legal obligation, excess liquidity appears and the interbank rate remains at the central bank main rate.

To sum up: neither the fixed-rate full allotment nor liquidity hoarding behavior by banks can explain the large increase in liquidity while the interbank rate was declining ${ }^{13}$. As shown now, fragmentation can. It does not necessarily mean that fixed-rate full allotment and liquidity hoarding by banks have played no-role in increasing liquidity on top of the increase due to fragmentation. It just mean that they have played no role in the decrease of the interbank rate.

\subsection{Fragmented banking system}

This subsection incorporates fragmentation in the model. Fragmentation is the fact that liquidity does not flow from one part of the monetary union to the other.

The origin of fragmentation is that some banks in the monetary union are considered risky (peripheral banks) while others are considered safe (core banks). To which group a given bank belongs depends on the country of origin of the bank and is observable. This difference in perceived credit risk, is related to possible losses made by peripheral banks, resulting from devaluation of their assets following for instance: tensions in the local sovereign debt market, increase in non-performing loans after a construction bubble or a large recession or expectations that the country will exit the monetary union and that deposits will be converted in a new currency. Since banking supervision is not yet completely harmonized in the Euro-Area, some national banking systems are necessarily more risky than others. Moreover, as long as banks benefit from the implicit or explicit guarantee of their home state, the difference in the credit risk of sovereigns translates into a difference in the credit risks of banks. The completion of the

\footnotetext{
${ }^{12} \mathrm{An}$ increase of the interest rate would be very unwelcome in times of stress. If $A$ is unstable and unknown from the central bank, the fixed-rate full allotment is a superior mechanism to allot liquidity because it allows the central bank to reach its operational target for the interbank rate.

${ }^{13}$ The fact that these two explanations are not satisfactory is also stressed in Hauck and Neyer (2010), in a different model, that notably does not encompass fragmentation.
} 
banking union in the Euro-Area should contribute to decreases fragmentation.

This risk directly causes fragmentation as described now. A bank lending to a peripheral bank can expect to recover $\left(1+\tilde{r}_{B}\right) \rho$, where $\rho \leq 1$ is the expected recovery rate on one Euro lent (it is equal to 1 when the loan is considered risk-free), and $\tilde{r}_{B}$ is the interest rate charged to risky banks. Since leaving money parked at the central bank is risk-less, it must be the case that: $\left(1+\tilde{r}_{B}\right) \rho>\left(1+r_{r}\right)$. The rate charged on an interbank loan cannot be higher than the marginal lending facility rate of the central bank as no bank would be willing to borrow above it. It follows that: $r_{X} \geq \tilde{r}_{B}$. These two conditions can be verified only when:

$$
\rho>\frac{1+r_{r}}{1+r_{X}}
$$

If $\rho$ is small (high probability of default) compared to the size of the corridor, there exists no interest rate $\left(\tilde{r}_{B}\right)$ such that a loan to a risky bank is possible. This means that for a given expected loss on a loan to another bank, too thin of a corridor (high values of $\frac{1+r_{r}}{1+r_{X}}$ ) can push risky banks out of the interbank market. This formalizes the argument according to which a narrow corridor is harmful to interbank market activity. In the case of the Euro-Area, $\frac{1+r_{r}}{1+r_{X}}$ taken for overnight transactions be equal to $\frac{1+\frac{-0.2}{360}}{1+\frac{0.3}{360}}=0.99999$ at time of writing.

This illustrates that even the slightest doubt over the ability of a bank to reimburse a loan can cut it off completely from the interbank market. In what follows, it is assumed that this condition is not respected for peripheral banks i.e. these banks will not be able to borrow from core banks and will instead have to borrow from the central bank. ${ }^{14,15}$ In short, fragmentation is the fact that liquidity is not circulating within the monetary union, because peripheral banks borrow only from the central bank.

A direct consequence of fragmentation is a deposit flight from the periphery to the core. It is represented in the model by an amount "F" of liquidity that is transferred from peripheral banks to core banks. This transfer of liquidity stems from the following chain of events. In a well integrated monetary union, current account imbalances can build up. Deficit countries

\footnotetext{
${ }^{14}$ The mechanism would still work if core banks just refused to lend to peripheral banks for other reasons that risk or if peripheral banks could only borrow up to a maximum amount to core banks.

${ }^{15} \mathrm{~A}$ question that naturally arises is why does the central bank lends at a lower rate than the private market would? There are several reasons for that. First, it might be the case that the central bank considers it is in a better position than the market assess credit risk. Second, the central bank has a superior recovery technology as it is senior to all other creditors by law. Third, the central bank being risk-free, it is able to set high haircut on the assets it accepts as collateral against its loans. This is not necessarily possible between private agents. For instance, if bank A borrows 10 euros from bank B against collateral with $90 \%$ haircuts meaning it has to post 100 of collateral, then bank A is exposed to the credit risk of bank B and to the risk of not being able to recover all the collateral posted (see Bindseil (2014)).
} 
buy goods and services to surplus countries thanks to loans granted by surplus countries. Such loans can take the form of interbank market loans or the purchase by surplus countries banks of securities in deficit countries. Therefore, money is sent by deficit countries to surplus countries in exchange of goods. Money goes back from surplus countries to deficit countries in exchange of a liability of the deficit country, clearing the balance of payments.

If a well integrated monetary union becomes suddenly fragmented, deficit countries will not be able to roll-over their loans from core banks. It means that once the loans arrive at maturity, peripheral banks have to pay them off, i.e. they have to send an amount of liquidity $\mathrm{F}$ to core banks. The only way for the loans to be paid-off in the absence of other source of financing would be for deficit countries to manage a current account surplus (by macroeconomic identity). As this is not possible overnight, the banks will need to obtain the liquidity to repay core banks in some other way. Deficit (or peripheral) banks borrow from the central bank to repay surplus (or core) banks. The fact that the interbank market became inaccessible for peripheral banks at a time when they had a large net liability toward core banks is empirically supported by the analysis of the international investment positions of these countries, as shown in appendix IV. ${ }^{16}$

Therefore, the perceived default risk on peripheral banks and $\mathrm{F}$ are two sides of the same coin. The level of $\mathrm{F}$ is exogenous in the model as it is largely pre-determined by past capital inflows into peripheral countries.

There is a mass one of each type of banks and the timing of the model is exactly the same as above.

\subsubsection{Recourse to central bank standing facilities}

As before banks will use the central bank marginal lending facility to cover reserve deficiency and the deposit facility to stock their excess reserves. (2) still holds in the two countries. Further, $Z^{i, y}$ is a variable that applies to bank $i \in[0 ; 1]$ in country $y=\{C, P\}$. With $\int_{0}^{1} Z^{i, y} d i=Z^{y}$ and $Z^{C}+Z^{P}=Z$. Then:

$$
X^{i, C}=\max \left\{K^{i, C}-\left(R^{i, C}+B^{i}-\epsilon^{i, C}+F^{i, C}\right) ; 0\right\}
$$

\footnotetext{
${ }^{16}$ The paper focuses on the interbank market to motivate the existence of $F$ as empirical evidence suggests that this is through this market that the deposit flight occurred in the Euro-Area (appendix IV). Of course, a household (or any non-bank agent) that withdraws the money deposited in an Italian bank to put it in a Dutch bank, would also be counted in $\mathrm{F}$ as it would impact the liquidity position of the Dutch and the Italian banking system.
} 


$$
X^{i, P}=\max \left\{K^{i, P}-\left(R^{i, P}-\epsilon^{i, P}-F^{i, P}\right) ; 0\right\}
$$

Now, only core banks can access the interbank market.

\subsubsection{Deposit shocks}

The model that follows describes a situation where banks are not homogenous. As above, banks in the core are subject to shocks $\epsilon^{i, C}$ 's. Fragmentation manifests itself before the start of the model as peripheral banks experience a deposit flight F. F unit of funds are shifted from peripheral banks to core banks. ${ }^{17}$ At the bank level, bank "i" in the core receives $F^{i, C}$ amount of funds and bank "i" in the periphery, loses $F^{i, P}$ units of funds.

There are two different expected profit functions:

$$
\begin{gathered}
E\left[\Pi^{i, C}\right]=-r_{D}\left(D^{i, C}+F^{i, C}\right)-r_{B} B^{i, C}-r_{M} M^{i, C}+r_{r}\left(R^{i, C}+F^{i, C}+B^{i, C}-K^{i, C}\right) \\
-\left(r_{X}-r_{r}\right) \int_{\hat{\epsilon}^{i, C}}^{\infty} g\left(\epsilon^{i, C}\right)\left(K^{i, C}-\left(R^{i, C}+B^{i, C}-\epsilon^{i, C}+F^{i, C}\right)\right) \mathrm{d} \epsilon^{i, C} \\
E\left[\Pi^{i, P}\right]=-r_{D}\left(D^{i, P}-F^{i, P}\right)-r_{M} M^{i, P}+r_{r}\left(R^{i, P}-F^{i, P}-K^{i, P}\right) \\
-\left(r_{X}-r_{r}\right) \int_{\hat{\epsilon}^{i, P}}^{\infty} g\left(\epsilon^{i, P}\right)\left(K^{i, P}-\left(R^{i, P}-\epsilon^{i, P}-F^{i, P}\right)\right) \mathrm{d} \epsilon^{i, P}
\end{gathered}
$$

The difference between the two profit functions, reflects the difference in period II and the fact that core banks experience inflows and peripheral banks outflows on their deposits $D^{i, y}$.

\subsubsection{Interbank market rate}

The interbank rate prevailing (recalling only core banks are on the interbank market) is still denoted $r_{B}$.

Following the same maximization and aggregation steps as above, the interbank rates in the core is:

$$
r_{B}^{\star}=r_{r}+\left(r_{X}-r_{r}\right)\left(1-G\left(R^{C}-K^{C}+F\right)\right)
$$

\footnotetext{
${ }^{17}$ Peripheral banks use funds from the central bank and their existing reserves to meet F. Alternatively, one could assume that banks sell their assets. This case is not considered as what matters is the aggregate liquidity in the periphery and in the core. If one assumes that core banks (or depositors of core banks) are not willing to purchases peripheral assets, then a peripheral bank would need to sell her assets to another peripheral bank or to the central bank. Selling to the former would not change the aggregate quantity of liquidity in the periphery while selling to the central bank might not be possible if the central bank is unwilling to buy as much assets as F.
} 
It would not be possible to have a rate that is strictly higher in the core than in the periphery because otherwise it would be profitable to borrow in the periphery and lend in the core. This asymmetry comes from the fact that fragmentation is itself asymmetric: it is not possible for peripheral banks to borrow from the core but it is possible for core banks to borrow from the periphery. Therefore, it must be the case that $r_{B} \leq r_{M}$. When $r_{B}=r_{M}$ things work as in the previous subsection, except that peripheral banks borrow more from their central bank (F units of funds more) and core banks less (F unit of funds less). The focus is on the more interesting case where $r_{B}<r_{M}$.

Using (25), for $r_{B}<r_{M}$, it must be the case that:

$$
F>K^{C}-R^{C}
$$

To determine when this is respected, one needs to solve for $R^{C}$.

\subsubsection{Central bank main refinancing operations}

When $E\left(r_{B}\right)<r_{M}$, core banks prefer borrowing on the interbank market than from the central bank. Therefore, $M^{C}=0$. This means that $R^{C}=O^{C}-C^{C}$. Using (26) one can see that it needs to be the case that:

$$
F>K^{C}+C^{C}-O^{C}
$$

Therefore:

$$
r_{B}<r_{M} \Leftrightarrow F>K^{C}+C^{C}-O^{C}
$$

It means that if the shift of deposits to the core is larger than core banks liquidity needs (reserve requirements plus demand for currency from the public net of central bank outright purchases), core banks will have no interest in going to the central bank. Core banks are actually saturated with liquidity. Additional liquidity inflows cannot be compensated by borrowing less at the refinancing operation (see diagram 3 in appendix). This triggers an excess of liquidity in the core that exerts a downward pressure on rates.

Proposition 3: In a fixed-rate full allotment regime, if the deposit flight is sufficiently large 
(F large), the interbank rate in the core will be strictly lower than the rate of the main refinancing operation $\left(r_{B}<r_{M}\right)$.

Therefore, in a fixed-rate full allotment regime:

$$
\begin{aligned}
& M^{P \star}=K^{P}+C^{P}-O^{P}+F \\
& M^{C \star}=\max \left\{0 ; K^{C}+C^{C}-O^{C}-F\right\}
\end{aligned}
$$

For high level of F equation (25) becomes:

$$
r_{B}^{\star}=r_{r}+\left(r_{X}-r_{r}\right)\left(1-G\left(F-C^{C}-K^{C}+O^{C}\right)\right)
$$

This equation shows that the interbank rate depends negatively on the level of the deposit flight. Using equation (4), (29) and (30), for high level of F:

$$
R^{\star}=F+K^{P}+O^{C}-C^{C}
$$

This contrasts with equation (15), where the equilibrium amount of reserves in the banking system was always equal to reserve requirements. Now, it increases with the size of the deposit flight $(F)$, outright purchases $\left(O^{C}\right)$ and decreases with the level of currency in circulation $\left(C^{C}\right)$ in the core. The interbank rate declines accordingly when reserves increase and vice versa. When $\mathrm{F}$ is large, core banks are saturated with liquidity and cannot compensate movements in currency or central bank purchases by asking more or less liquidity to the central bank (they always borrow zero). Peripheral banks borrow just enough to satisfy their reserve requirements. Peripheral banks finance themselves at the central bank main rate, strictly higher than the interbank rate, at which core banks can borrow.

\section{Policy Implications}

Several policy implications can be derived from the model.

First, whether there is fragmentation or not depends to some extent on the central bank. 
More precisely, it depends on this condition:

$$
\rho>\frac{1+r_{r}}{1+r_{X}}
$$

If $\rho$ is small (high probability of default) compared to the size of the corridor, then peripheral banks rather borrow from the central bank than from the interbank market and the mechanics described in subsection 2.3 applies. The central bank has an impact on whether there is fragmentation or not since it sets the size of the corridor. A larger corridor (small $\frac{1+r_{r}}{1+r_{X}}$ ) implies less fragmentation, but this would also mean that peripheral banks finance themselves at a higher rate. Therefore, the central bank faces a trade-off between keeping the interbank market alive and preventing financing conditions to diverge across the monetary union. ${ }^{18}$ This trade-off is more or less acute depending on the size of $\rho$. At the height of the crisis, in July 2012, the perceived risk to lend to a peripheral bank was probably so high (very low $\rho$ ) that even if the central bank had an extremely large corridor (low $\frac{1+r_{r}}{1+r_{X}}$ ), (33) would not have been fulfilled and peripheral banks would still have been excluded from the market. At that time, widening the corridor would have only increased financing costs of peripheral banks without improving the functioning of the interbank market. Since then, perceived credit risk has probably diminished. It is likely that as of today, a larger corridor could have positive effects on interbank market activity. Therefore, a full recovery of the interbank market and hence a reduction in central bank lending and TARGET2 probably require the Eurosystem to provide liquidity to banks under stricter conditions.

With fragmentation, the interbank rate, a key channel of monetary policy fluctuates according to two elements that are beyond the control of the central bank: the level of the deposit flight and the demand for currency from the public. This can trigger sudden tightening or loosening of monetary conditions. The remainder of this section discusses how such fluctuations can be avoided.

Recall that restricting the quantity of liquidity would be useless for this purpose. Whatever the quantity allotted, most of it would be taken by peripheral banks in order to cover the liquidity flight to core banks. For low levels of fragmentation, what is not borrowed at the central bank by core banks is borrowed by peripheral banks and the rate remains at the targeted level.

\footnotetext{
${ }^{18}$ The fixed-rate full allotment implies that peripheral banks would choose to go the central bank when the interest rate they face on the interbank market is higher than the main rate $\left(r_{M}\right)$ instead of the marginal lending facility rate $\left(r_{X}\right)$. Therefore, the fixed-rate full allotment acts on interbank market activity just as a thinner corridor would.
} 
Past a certain threshold, core banks would ask zero to the central bank and would still have too much liquidity from the deposit flight. Interbank rate would decline accordingly. Peripheral banks, depending on which quantity is allotted would need to top-up what they take at the main refinancing operation with borrowings from the marginal lending facility. It is an interesting insight of the model that even without the fixed-rate full allotment, there can be an excess of liquidity and a volatile interbank rate.

The most obvious solution to the volatility of the interbank rate would be to equate the rates of the standing facilities (i.e. a corridor width of 0). This would suppress any kind of overnight interbank market. The central bank would then have to increase substantially the amount of loans granted to banks. It would then be crucial that banks have enough collateral to borrow from the central bank.

The central bank can decide to inject liquidity through asset purchases (increasing " $O$ " " in equation (25)). This would lower the interbank rate to the deposit facility rate. The most relevant rate for monetary policy would then be the deposit facility rate. This is what happened in the UK and to some extent in the US during the crisis (see Bech and Klee (2011)). A massive increase in assets purchased (or "Quantitative Easing") pushed the interbank rate to the floor. Buying assets allows to inject liquidity beyond what banks demand (Bindseil (2014)). A practical problem is that a large, safe and liquid asset market needs to be available to the central bank.

The model helps to understand whether the asset purchase programs announced by the ECB in January 2015 will indeed manage to increase liquidity. It suggests that peripheral banks might use some of the liquidity injected to decrease their borrowings from the central bank while core banks cannot do that as they borrow zero from the central bank. The liquidity injected in the periphery will be offset by lower borrowings from peripheral banks while the liquidity injected in the core would stay in the banking system and decrease rates.

If the central bank cannot increase liquidity to anchor the interbank rate at the deposit facility rate, it could try to withdraw liquidity to anchor the interbank rare at the main rate. How can a central bank that has committed to lend to banks as much as they wish withdraw liquidity? How in a system where the amount of liquidity provision is determined by banks on the basis of their liquidity needs, the central bank can lower the amount of liquidity? In a model with a well integrated banking sector, this would actually be impossible. Absorption operations (equivalent in liquidity terms to the central bank selling assets) would have no effect 
on aggregate liquidity, as banks compensate one-for-one liquidity absorbed by borrowing more to the central bank. Alternatively, in the presence of fragmentation, these operations are not neutral. This should not come as a surprise as this is economically the opposite operation to buying assets. The basic intuition is the same: core banks are unable to compensate liquidity movements from the central bank because they are overwhelmed with liquidity. There are however some differences, as explained now.

In the Euro-Area, absorption operations take the form of deposits made by banks at the central bank. ${ }^{19}$ These deposits are adjudicated according to a sealed bid auction. Bids contain a rate and a quantity. Banks bidding at the lowest rates are chosen first until the quantity of deposits the central bank intends to collect $(\underline{S})$ is reached. Each selected bank receives the rates it bids for if it is selected. No bid above the main rate $\left(r_{M}\right)$ are considered.

In the model, it means that these funds are deposited before the interbank market opens (contrary to the deposit facility) and then cannot be used for interbank loans. The funds are remunerated at $r_{S} \leq r_{M}$.

Denoting the size of absorption operations also called sterilization operations by " $\mathrm{S}$ " (with $S>0$ ), now it is the case that:

$$
M^{C \star}=\max \left\{K^{C}+C^{C}-O^{C}-F+S ; 0\right\}
$$

For low values of $\mathrm{F}$, absorption operations ( $\mathrm{S}$ ) increases the amount borrowed at the refinancing operations and aggregate liquidity does not change (banks compensate). Past a certain threshold, core banks borrow zero anyway, so locally, no compensation can occur and absorption operations are successful in decreasing the amount of liquidity and increasing interbank rates. This threshold is defined below. Using equation (31):

$$
F>K^{C}-O^{C}+C^{C}+\underline{S} \Leftrightarrow r_{S}=r_{B}<r_{M}
$$

Since lending to another core bank or subscribing to the central bank absorption operations are two risk-less options for core banks, at equilibrium they will have the same remuneration. Figure 9 in appendix shows that this was indeed the case when the Eurosystem was conducting

\footnotetext{
${ }^{19}$ It is assumed that these operations take the same form as the ones conducted between May 2010 and June 2014. The absorption operations were limited in size because they aimed specifically at absorbing the liquidity injected through asset purchases made under the securities markets program (SMP). In the scheme proposed here, the size of the operations could be unlimited.
} 
liquidity absorbing operations. Between 2010 and 2014, the rate on sterilization certificates was moving closely with the interbank rate (much more closely than standing facility rates or the main rate). This stresses the importance of sterilization operations in steering the interbank rate when there is excess liquidity due to fragmentation.

This means that if fragmentation is high and absorption operations not too large, core banks that do not borrow from the central bank, will be able to park their liquidity at a rate strictly below the main policy rate. ${ }^{20}$ This is not the case of peripheral banks for whom it would not be profitable since they finance themselves by borrowing from the central bank at the main rate. ${ }^{21}$ Therefore, money demand from peripheral bank is unchanged compared to when there is no sterilization.

Absorption operations work similarly to assets purchases. A key difference though, is that in the case of absorption operations, banks self-select: only core banks participate.

Proposition 4: When the deposit flight $(F)$ is large enough, increasing the size of the sterilization operations, decreases excess liquidity in the core, even when banks can borrow as much as they wish from the central bank.

\section{Testing the predictions of the model}

The model replicates the main stylized facts of monetary policy in the Euro-Area: the endogenous increase in liquidity since the crisis and the simultaneous decline of the interbank rate (without the central bank intending to increase the supply of liquidity). This section shows in a systematic manner that the main predictions of the model are fulfilled. The main predictions of the model are:

\section{Prediction 1: There is a stable relationship between excess liquidity (total liquidity minus}

\footnotetext{
${ }^{20}$ Appendix VI shows what happens when absorption operations become large.

${ }^{21}$ The fact that only core banks participate to sterilization operations is confirmed by looking at the balance sheets of the main central banks of the Euro-Area. One can see that at the end of 2011, banks located in Germany, France, Netherlands, Belgium, Austria, Finland and Luxembourg accounted for $97 \%$ of all sterilization operations, against $2 \%$ for banks located in Spain, Italy, Greece, Ireland, Portugal and Cyprus. At the end of 2012 the picture is even more clear: $100 \%$ against $0 \%$ (see the financial statement in the annual reports 2011 and 2012 of these central banks). These two groups of countries are made according to a simple criteria: those who benefited from external support (International Monetary Fund, European Financial Stability Facility or European Stability Mechanism programs) since 2008 and the others. This allows to isolate countries that had a sovereign and/or a banking crisis and thus were likely cut-off from the Euro-area interbank market (the peripheral countries).
} 
reserve requirements) and the interbank rate (equations (11) and (31)).

Prediction 2: Since the crisis, peripheral banks borrow more from the central bank than they keep as reserves. It is the opposite for core banks (equations (29) and (30)).

Prediction 3: Fragmentation increases excess liquidity and consequently decreases interbank rates (equations (32) and (31)).

Prediction 4: Absorption operations, in the context of fragmentation, can contribute to reduce excess liquidity and increase interbank rates, even with fixed-rate full allotment (equation (35) below).

\subsection{Prediction 1: the relationship between excess liquidity and the inter- bank rate}

This subsection shows that the simple model developed above is able to capture the relationship between the level of the interbank rate and the amount of liquidity in the banking system.

Note that surprisingly, according to the theoretical model, this relationship should not have changed with the crisis. Looking at equations (11) and (31), which are equilibrium conditions taking into account the maximization process of banks with and without fragmentation, one can see that the interbank rate is a simple function of excess liquidity. Indeed, in the two cases, the interbank rate is equal to the deposit facility rate, plus the corridor times a normal cumulative distribution function that takes as input the level of excess liquidity. Excess liquidity is defined as total bank reserves minus minimum reserve requirements.

The theoretical model predicts that before the crisis, the interbank rate should respond to excess liquidity in the whole monetary union while after the crisis it should respond to excess liquidity in the core (since only core banks transact on the interbank market). However, the model also predicts that in case of fragmentation, excess liquidity should be zero in the periphery and should be positive in the core. Therefore, total excess liquidity is equal to excess liquidity in the core.

Figure 4 compares the predicted interbank rate if one plugs data on excess liquidity in equa- 
Figure 4: Predicted EONIA vs actual (Maintenance period average, percentage points)

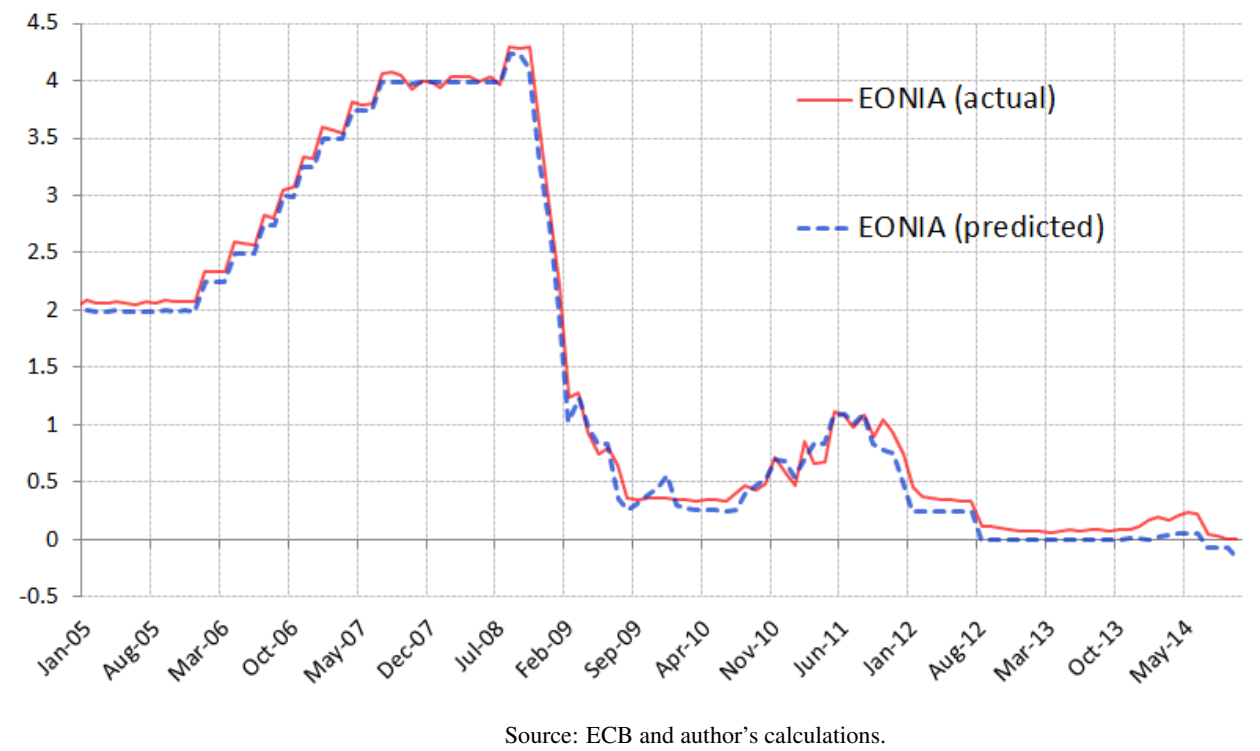

tion (11) and actual interbank rate data. ${ }^{22}$ Data on standing facility rates and excess liquidity come from the ECB statistical data warehouse. $\mathrm{G}($.$) is the cumulative distribution function$ of a normal distribution with mean 0 . The standard deviation of this distribution, is constant throughout the whole period at EUR $80 \mathrm{bn}$. It is chosen such that the interbank rate is at the middle of the corridor before the crisis. It is in line with the one used by the ECB before the crisis (Gonzalez-Paramo (2007)).

The model seems indeed to capture well the relationship between liquidity and the interbank rate. The mean square error is 1.2 basis point. The EONIA deviates more from its predicted value after October 2008 (start of the crisis) compared to before (the mean square error is 1.7 basis point $v s 0.5$ basis point), suggesting that the relationship could have been impacted marginally. This prediction is much better than what a naive guess, that assumes the EONIA equates the main rate, delivers (mean square error of 15 basis points over the whole period and 26 basis points after the crisis). After the crisis, the EONIA is more often above its predicted value, which suggests that either banks that have access to the market incur a risk premium or that some banks are keeping some precautionary liquidity buffer that they are not ready to trade. It is also likely that during the crisis the function $G($.$) has changed and that its variance$ has increased.

This chart tells us that the simple model developed above performs well to explain the dynamics of the interbank rate, using data on excess liquidity. It also tells us that in order to

\footnotetext{
${ }^{22}$ As proxy for the interbank rate, the EONIA is used. EONIA observations are averaged over the maintenance period. That is the period over which bank reserves are averaged to calculate minimum reserve requirements.
} 
understand the dynamics of the interbank rate, one needs to understand the dynamics of excess liquidity.

\subsection{Prediction 2: the repartition of liquidity within the Euro-Area: the TARGET2 imbalances}

Prediction 2 states that liquidity should be distributed in an heterogeneous manner in the EuroArea. The magnitude of this heterogeneity is represented by $\mathrm{F}$ in the model.

Data from the balance sheet of national central banks (see Natixis (2014) for a time series of these data in the case of Spain and Italy) show that peripheral banks borrow much more from their central bank than they deposit since the crisis. This means that the liquidity has indeed left these countries.

An alternative way to understand this phenomenon is to look at the "TARGET2 imbalances".

The Eurosystem operates in a decentralized manner. Commercial banks have their account and borrow from their home central bank (i.e. Deutsche Bank in Germany with the Bundesbank and Unicredit in Italy with the Banca d'Italia). Banks can make payments across the monetary union, transferring Euros on different accounts held at central banks. Transfers between accounts held at two different central banks goes through the Euro-Area payment system, named TARGET2. ${ }^{23}$ Transactions on TARGET2 are made via central banks. In the (likely) case where the banks of country A send more money to other countries via the TARGET2 payment system than they receive, a "TARGET2 liability" appears on the balance sheet of the central bank of country A. The country receiving more money than what it is sending, gets a "TARGET2 asset”. At first sight, TARGET2 imbalances (measured as the sum of all TARGET2 assets that by identity has to be equal to the sum of all TARGET2 liabilities) just keep track of imbalances in the payment system.

TARGET2 imbalances can also be interpreted in an economic way. In a well integrated monetary union, current account imbalances can build up. Deficit countries buy goods and services to surplus countries thanks to loans granted by surplus countries. Such loans can take the form of interbank market loans or the purchase by surplus countries banks of securities in deficit countries. Therefore, money is sent by deficit countries to surplus countries in exchange

23"TARGET2" stands for the second version of the Trans-European Automated Real-time Gross settlement Express Transfer system. 
of goods. Money goes back from surplus countries to deficit countries in exchange of a liability of the deficit country, clearing the balance of payments.

If a well integrated monetary union becomes suddenly fragmented, deficit countries will not be able to roll-over their loans from core banks. It means that once the loans arrive at maturity, peripheral banks have to pay them off. The only way for the loans to be paid-off in the absence of other source of financing would be for deficit countries to manage a current account surplus (by macroeconomic identity). As this is not possible overnight, the banks will need to obtain the liquidity to repay core banks in some other way. In any case, this will result in one-way payment flows, i.e. TARGET2 imbalances. Banks in deficit countries finance these flows by borrowing more from their central bank. On the contrary, surplus countries banks will accumulate more reserves on their accounts at central banks. Countries subject to a deposit flight, as described above will have a TARGET2 liability. Countries recipients of funds, a TARGET2 asset.

TARGET2 imbalances (as measured by the sum of all TARGET2 assets) are a direct measure of the deposit flight, which is itself the cause of the uneven recourse to central banks borrowings in different countries. Therefore, TARGET2 imbalances are used as a proxy for $\mathrm{F}^{24}$

Figure 5 shows the breakdown of TARGET2 claims during the crisis. They indeed increased substantially since 2008. Also, the net recipients of capital (the core countries) are indeed countries perceived as extremely safe and with positive international investment positions. Note that the decrease of TARGET2 imbalances since 2012 is not necessarily a sign of a better integration. It can very well be that deficit countries (peripheral countries) are still cut from the interbank market but run current account surpluses since the crisis.

Contrary to what has sometimes been said in the literature, it is not obvious that TARGET2 imbalances depend on the liquidity policy of the central bank. In a fixed-rate full allotment regime, peripheral banks go the main refinancing operations to meet the deposit flight. In a limited liquidity setting, they could also use the marginal lending facility. The result would be the same as regards TARGET2 imbalances but peripheral banks would just pay a higher rate on their central bank borrowings. TARGET2 imbalances are impacted by the fixed-rate full allotment to the extent that the fixed-rate full allotment worsens fragmentation, as discussed in section 3 .

\footnotetext{
${ }^{24}$ There are some technical differences in practice between TARGET2 and F, as discussed in appendix VII.
} 
Figure 5: Evolution of TARGET2 claims during the crisis (EUR bn)

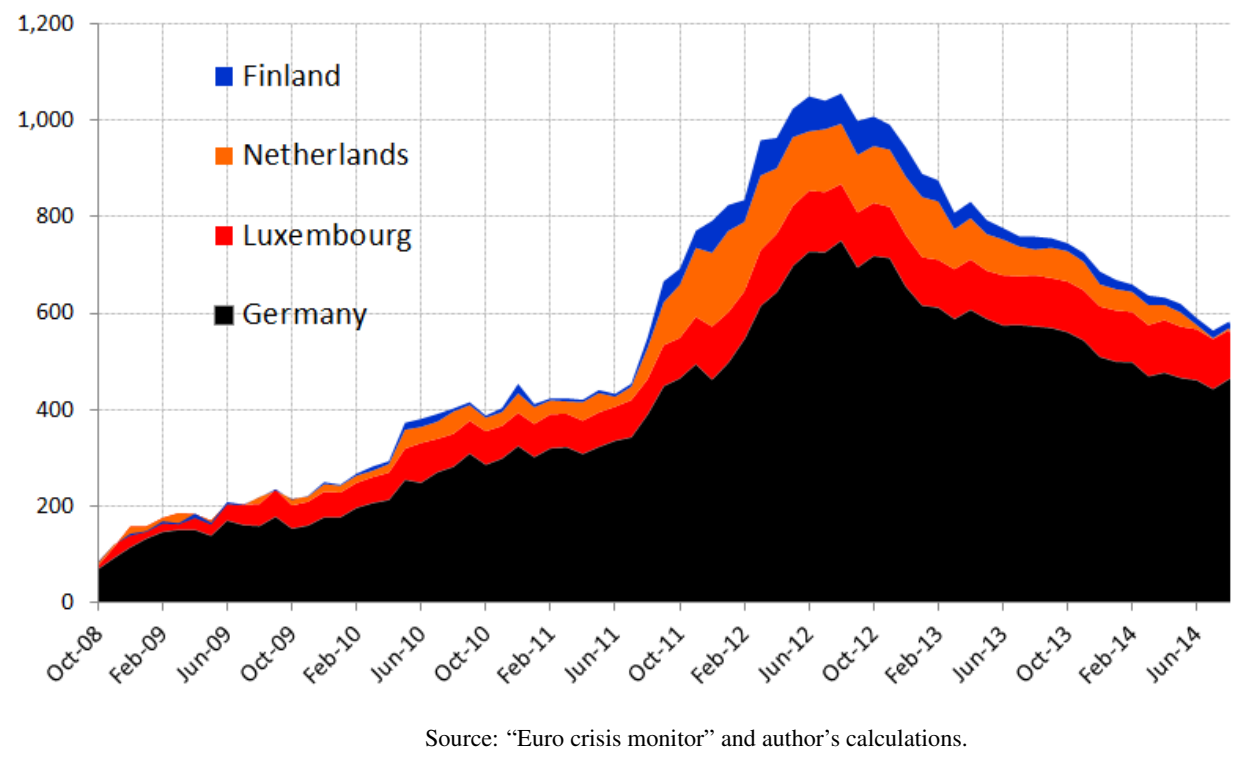

\subsection{Predictions 3 and 4: the effect of fragmentation and absorption oper- ations on liquidity}

The main theoretical mechanism of the paper states that as F increases, liquidity should increase. The corresponding policy implication, is that absorption operations, in the context of fragmentation, can be effective in reducing liquidity even if banks can borrow as much as they wish from the central bank. These two assertions are tested now.

\subsubsection{Methodology}

In order to test predictions 3 and 4, equation (32) is used. Taking into account sterilization operations yields:

$$
R^{\star}=F+O^{C}-C^{C}+K^{P}-S
$$

This condition states that the level of aggregate reserves banks have on their accounts at the central bank depends on the level of the deposit flight $\mathrm{F}$, outright purchases made by the central bank in the core, the amount of currency in circulation in the core, minimum reserve requirements in the periphery and the size of sterilization operations. This relationship is an equilibrium condition taken from the model. Recall that without fragmentation, at equilibrium, aggregate reserves $R$ should just be equal to minimum reserve requirements (as in equation (15)) and in this case most right-hand side variables should have no effect on reserves. 
The general econometric specification reads as follow:

$$
R_{t}=\alpha+\beta_{1} F_{t}+\beta_{2} O_{t}+\beta_{3} C_{t}+\beta_{4} K_{t}+\beta_{5} S_{t}+\epsilon_{t}
$$

Subscripts $t$ indicate the timing of the variables with respect to each other. The first differences of level variables are used in order to avoid unit roots. Two types of regression are run: OLS and 2SLS.

The left-hand side variable, $R$ is the total reserves of banks at the central bank. It is the sum of all Euros that can be used for overnight interbank loans, that are held on accounts of commercial banks at Eurosystem central banks measured after the payment system is closed.

TARGET2 imbalances (as measured by the sum of all TARGET2 assets) are used as a proxy for F. Recall that TARGET2 imbalances measure the deposit flight from the periphery to the core. The deposit flight depends on the perceived risk from investors of leaving their money in the periphery and of how much money they left in the periphery in the first place, i.e. the net liability position of peripheral countries toward core countries. The net liability position of peripheral countries is by large predetermined at the time the crisis hit. The extent of the flight of this pre-determined invested money depends on fragmentation. Fragmentation itself depends on perceived credit risk on peripheral countries.

Perceived credit risk, independently of TARGET2 is controlled for, using spreads of Spanish and Italian 10-year government bonds vs Germany. This intends to check that TARGET2 captures only the deposit flight from periphery to the core and not some liquidity hoarding motive resulting from investor's fear of financial markets breakdown. This variable is called "Spreads". For both $F_{t}$ and "Spreads" a positive sign is expected. The coefficient of F should be close to one.

The size of sterilization operations, $S_{t}$, is set by the central bank. If the theoretical model is correct, its coefficient will be negative (and close to minus one). If the mechanism described above is not at work, the coefficient will be zero (i.e. liquidity absorbed by the central bank pushes banks to borrow more resulting in a zero net effect). Sterilization operations respond in part to purchases by the central bank (which is controlled for) under the "Securities Markets Programme" (ECB (2010)).

Assets purchases, $O_{t}$, if the theory is correct should increase the amount of reserves. If the theory is wrong, it should have no effect (increased purchases injects liquidity pushing banks to borrow less from the central bank resulting in a zero net effect). "O" includes mostly assets 
purchased under the "Securities Markets Programme" (SMP) and the "Covered Purchases Programmes" (CBPPs). ${ }^{25}$ These purchase programmes responded to tensions in financial markets, which is controlled for.

Notably, the 3-month EURIBOR-OIS spread is used to control for financial markets turmoil and to capture possible liquidity hoarding motives. "EURIBOR-OIS" measures the premium that banks charge to each other for a 3-month loans compared to an overnight loan. It should increase as bank feel unsecured and as they hoard liquidity (Acharya and Skeie (2011)). Its coefficient should be positive.

The level of reserve requirements, $K_{t}$ are changed by the Eurosystem once a month for large banks and quarterly for small ones. They are calculated as one percent of the "reserve base" with a 3-month lag. The reserve base represents banks' short term liabilities as of 3 months before. Required reserves are remunerated by the central bank such that it is not profitable to change its reserve base (ECB (2013a)). Overall, $\mathrm{K}$ is quite stable and is likely to be taken as exogenous by banks. Its coefficient should be positive.

According to the model currency in circulation in the core $C_{t}$ when going up, should relieve core banks from some excess liquidity and therefore lower aggregate liquidity (negative coefficient). If on the other hand there is no fragmentation, increase in demand for currency is matched by higher recourse to central bank operations. Then the coefficient should be zero. Currency in circulation is seen by central banks as an "autonomous factors", i.e. something taken as exogenous by central banks and banks.

Banks tend to hoard liquidity at the end of the year in order to embellish end-of-year statement to appear cash-rich (see Allen and Saunders (1992) or Bindseil et al. (2003)). In order to capture this, "End-of-year" is a dummy variable, equal to one when the maintenance period goes over year-end and 0 otherwise.

Right-hand side variables can be considered exogenous. Controls are in place and there is no reason to think about reverse causality, except for TARGET2.

Some authors indeed argue that TARGET2 imbalances are created as a result of a balance sheet identity of the central banks (Whelan (2014)). Rather, the present paper argues that TARGET2 imbalances arise purely from the deposit flight, itself triggered by factors that affect the left-hand side variable through TARGET2 and other controls. This paper strongly defends the view that TARGET2 imbalances are a sign of the deposit flight and trigger the use of central

\footnotetext{
${ }^{25}$ The asset-backed securities purchases programme (ABSPP), started after the period covered by the data.
} 
bank operations and not the opposite, i.e. TARGET2 are exogenous in the regressions. As a robustness check, it is useful to find an instrument for TARGET2 that would not depend directly on the balance sheet of the central bank. Therefore, a two-stage least square procedure is used. In the first step, the instrument is used to estimate TARGET2 imbalances.

The phenomenon that this instrument should capture, is the case where an agent (irrespective of her nationality), actively moves her money from a euro-area peripheral country to the core. For this purpose, an indicator of cross-border lending is constructed. This indicator is equal to all securities held by banks located in countries with a consistent TARGET2 asset through the crisis (namely Germany, Netherlands, Luxembourg and Finland, see figure Figure 5), which has been issued in another Euro-Area country. As stressed in appendix IV, the analysis of the international investment positions of peripheral countries indicates that securities holdings have played a large role in the deposit flight in peripheral countries during the crisis. When these holdings are going down, this means $\mathrm{F}$ goes up and fragmentation is increasing. This assumes that the decrease is driven by the decrease in supply of funds from core countries and not by a willingness from peripheral countries to deleverage (supply vs demand driven decrease in quantities). ${ }^{26}$

\subsubsection{Data}

$R, O, S, C, K$ and cross-border lending are taken from the ECB statistical data warehouse.

The five first variables involve Eurosystem's passive or active participation. Therefore, they are unlikely to be subject to any kind of measurement errors.

An empirical challenge is that except for cross-border lending, these variables are not available on a country per country basis. Theoretically, this does not matter for $S$ or for $R$ as the variations of these series should come from the core exclusively. For $O, C$ and $K$, this is more problematic because only the share of these variables that applies to core countries should explain the left-hand side variable. If the movements of these variables is positively correlated between core and peripheral countries (e.g. demand for currency goes up in the core and the periphery at the same time), this would just results in the coefficients to be driven toward zero, but they should still be significant. If these variables are not correlated, this could result in the coefficients to be insignificant. There is no reason to believe that the variables should be negatively correlated across the monetary union.

\footnotetext{
${ }^{26}$ If the decrease in equilibrium quantities of loans to the periphery was mainly demand driven, then a decrease in yields would have been observed. It is of course the opposite that happened during the crisis.
} 
Except from currency in circulation, other items affect the aggregate liquidity position of the banking system without being directly related to bank's borrowings. These items are called "autonomous factors". Autonomous factors are classified in four categories: Currency in circulation, Net foreign asset of the central bank, government deposits and other autonomous factors (ECB (2002)). For consistency, one may wish to include them all together. However, only currency in circulation and Net foreign assets are included in the regressions (as "C"). Government deposits at the central bank and other autonomous factors are not included because they are likely to affect peripheral countries relatively more than core countries. Indeed, looking at the balance sheet of central banks, it seems that by far the largest and most volatile government deposits are in Italy. Other autonomous factors include the Emergency Liquidity Assistance (ELA), which should arguably be granted to distressed banks exclusively.

The indicator on cross-border lending is made of country per country data. The quality of these data is ensured by the fact that they are used by the Eurosystem to compute a crucial economic indicator: M3. Therefore, non-reporting or non-compliant banks are fined.

Sovereign spreads and EURIBOR-OIS computed using daily end-of-day data from Bloomberg. "Spreads" is the arithmetic unweighted average of Italian and Spanish 10-year generic government bond yield spread over their German counterpart. Other peripheral government bonds could have been included but this would have been detrimental to the quality of the data as other peripheral countries do not have generic 10-year government bond outstanding from 2008 to 2014.

Data on TARGET2 are taken from www.eurocrisismonitor.com that collects the data from national central banks' websites.

All these variables are averaged over the maintenance period (roughly a month) using endof-day values, except for TARGET2 and cross-border securities holdings for which only endof-month data are available.

The Augmented Dickey Fuller test confirms that first differentiated variables have no unit root. It is preferable to run the regressions from October 2008, as the drivers of total liquidity, central bank liquidity and interbank rates are well known before 2008. Hence, the sample runs from October 2008 to September 2014. There are 71 observations. 
Table 1: OLS (dependent variable: banks' reserves)

\begin{tabular}{lclll}
\hline \hline Deposit flight $(F)$ & $0.72^{* * *}$ & $0.73^{* * *}$ & $0.75^{* * *}$ & $0.78^{* * *}$ \\
& $(0.2)$ & $(0.19)$ & $(0.18)$ & $(0.19)$ \\
Currency $(C)$ & -0.28 & -0.37 & -0.15 & -0.14 \\
& $(0.25)$ & $(0.24)$ & $(0.25)$ & $(0.25)$ \\
Sterilization $(S)$ & $-1.23^{* * *}$ & $-1.13^{* * *}$ & $-0.94^{* *}$ & $-0.94^{* *}$ \\
& $(0.41)$ & $(0.39)$ & $(0.39)$ & $(0.39)$ \\
Outright purchases $(O)$ & 0.96 & 0.77 & 0.42 & 0.45 \\
& $(0.64)$ & $(0.61)$ & $(0.6)$ & $(0.61)$ \\
Required reserves $(K)$ & 0.34 & 0.31 & 0.11 & 0.18 \\
& $(0.48)$ & $(0.46)$ & $(0.45)$ & $(0.47)$ \\
End-of-year & & $55,288^{* * *}$ & $60,441^{* * *}$ & $59,515^{* * *}$ \\
& & $(20,138)$ & $(19,502)$ & $(19,709)$ \\
EURIBOR-OIS & & & $109,071^{* *}$ & $112,3491^{* *}$ \\
& & & $(44,364)$ & $(45,121)$ \\
Spreads & & & & $-10,880$ \\
& & & & $(21,985)$ \\
\hline$R^{2}$ & 0.29 & 0.36 & 0.42 & 0.42 \\
Adjusted $R^{2}$ & 0.23 & 0.30 & 0.35 & 0.35 \\
\hline \hline
\end{tabular}

Standard deviations in parenthesis

$* p<0.10, * * p<0.05, * * * p<0.01$

Table 2: 2SLS (instrument for deposit flight: cross-border securities holdings)

\begin{tabular}{lclll}
\hline \hline Deposit flight $(F)$ & $1.84^{* *}$ & $1.07^{* *}$ & $0.92^{* *}$ & $1.06^{*}$ \\
& $(0.73)$ & $(0.5)$ & $(0.46)$ & $(0.59)$ \\
Currency $(C)$ & -0.36 & $-0.40^{*}$ & -0.16 & -0.14 \\
& $(0.29)$ & $(0.23)$ & $(0.24)$ & $(0.24)$ \\
Sterilization $(S)$ & $-1.83^{* * *}$ & $-1.32^{* * *}$ & $-1.03^{* *}$ & $-1.08^{* *}$ \\
& $(0.61)$ & $(0.46)$ & $(0.43)$ & $(0.46)$ \\
Outright purchases $(O)$ & -0.35 & 0.37 & 0.21 & 0.17 \\
& $(1.1)$ & $(0.81)$ & $(0.77)$ & $(0.80)$ \\
Required reserves $(K)$ & 0.55 & 0.38 & 0.14 & 0.29 \\
& $(0.58)$ & $(0.45)$ & $(0.43)$ & $(0.5)$ \\
End-of-year & & $55,845^{* * *}$ & $60,800^{* * *}$ & $59,118^{* * *}$ \\
& & $(19,633)$ & $(18,525)$ & $(18,760)$ \\
EURIBOR-OIS & & & $110,763^{* * *}$ & $118,119^{* * *}$ \\
& & & $(42,300)$ & $(44,404)$ \\
Spreads & & & & $-21,756$ \\
& & & & $(29,996)$ \\
\hline$R^{2}$ & & 0.33 & 0.41 & 0.40 \\
\hline \hline
\end{tabular}

Standard deviations in parenthesis

$* p<0.10, * * p<0.05, * * * p<0.01$

\subsubsection{Results}

As one can see from tables 1 and 2, all significant coefficients have the expected sign and expected magnitude. Durbin-Watson and endogeneity tests are conclusive. Deposit flight $(F)$ is 
always positive, significant and close to one. Sterilization operations $(S)$ are always significant, correctly signed and close to minus one (as theory predicts).

Currency in circulation in the core $(C)$, minimum reserve requirements in the periphery $(K)$, and outright purchases in the core $(O)$ have the expected signs (except for $O$ in the first 2SLS regression) but are not significant (except for $C$ in the second 2SLS regression). This comes likely from the imperfect proxies used (total value instead of country-per-country).

"Spreads" is not significant showing that it is not the stress on financial markets that drives the results, but rather that fragmentation, proxied by TARGET2, is key to understand liquidity in the Euro-Area.

Note at last the significant and large (around EUR 60 bn) End-of-year effect. Also, there is a role in the sample for liquidity hoarding or precautionary demand of liquidity to the central bank, as the 3-month EURIBOR-OIS spread is strongly significant and large.

These results are all extremely supportive of the theoretical model laid out above.

\section{Conclusion}

This paper shows how fragmentation disrupts monetary policy implementation. It explains how excess liquidity arises endogenously in the banking system and causes the short term interest rate to fluctuate beyond the control of the central bank.

When perceived credit risk between banks is elevated, the central bank by providing large amount of liquidity at favorable conditions, prevents financing costs to diverge substantially between countries. By doing so, it also discourage interbank market activity and increases fragmentation. In this sense, it faces a trade-off between reducing fragmentation and preventing financial conditions to diverge across the monetary union.

Asset purchases can help to steer the interbank rate toward the deposit facility rate. However, some of the liquidity injected via purchases will be offset by banks, which will borrow less to the central bank. Therefore, the central bank needs to purchase a large amount of assets (larger than the liquidity needs of the banking system). This is an often overlooked channel by which the Quantitative Easing of the ECB can lower interest rates.

On the other hand, using absorption operations can be an effective way to reduce excess liquidity and stabilize the interbank rate.

The model has incidentally shown that even if the central bank provides liquidity under 
favorable conditions to peripheral banks, they still finance themselves at a slightly higher rate (the main rate) than core banks (the interbank rate). The gap can be closed using liquidity absorbing operations.

The model also shows that TARGET2 imbalances are a concrete manifestation of fragmentation and could also arise under stricter liquidity policy from the central bank.

Empirical evidence supports the theoretical mechanism described in the paper.

This mechanism is extremely general and could apply to any currency area that is financially fragmented. 


\section{References}

Acharya, Viral V. and David Skeie (2011): A model of liquidity hoarding and term premia in inter-bank markets. Journal of Monetary Economics, 58(5), pp. 436-447.

Afonso, Gara and Ricardo Lagos (2015): Trade Dynamics in the Market for Federal Funds. Econometrica, 83(1), pp. 263-313.

Allen, Linda and Anthony Saunders (1992): Bank window dressing: Theory and evidence. Journal of Banking $\mathcal{F}$ Finance, 16(3), pp. 585-623.

Auer, Raphael A. (2014): What drives TARGET2 balances? Evidence from a panel analysis. Economic Policy, 29(77), pp. 139-197.

Bech, Morten L. and Todd Keister (2013): Liquidity regulation and the implementation of monetary policy. BIS Working Papers 432, Bank for International Settlements.

Bech, Morten L. and Elizabeth Klee (2011): The mechanics of a graceful exit: Interest on reserves and segmentation in the federal funds market. Journal of Monetary Economics, 58(5), pp. 415-431.

Bianchi, Javier and Saki Bigio (2014): Banks, Liquidity Management, and Monetary Policy. Staff Report 503, Federal Reserve Bank of Minneapolis.

Bindseil, Ulrich (2014): Monetary Policy Operations and the Financial System. OUP Catalogue. Oxford University Press.

Bindseil, Ulrich, Gonzalo Camba-Méndez, Astrid Hirsch and Benedict Weller (2004): Excess reserves and implementation of monetary policy of the ECB. Working Paper Series 0361, European Central Bank.

Bindseil, Ulrich, Benedict Weller and Flemming Wuertz (2003): Central Bank and Commercial Banks' Liquidity Management - What is the Relationship? Economic Notes, 32(1), pp. 3766.

Blenck, Denis, Harri Hasko, Spence Hilton and Kazuhiro Masaki (2001): The main features of the monetary policy frameworks of the Bank of Japan, the Federal Reserve and the Eurosystem. In: Bank for International Settlements (ed.), Comparing monetary policy operating 
procedures across the United States, Japan and the euro area, BIS Papers chapters, vol. 9, pp. 23-56. Bank for International Settlements.

Borio, Claudio and William Nelson (2008): Monetary operations and the financial turmoil. BIS Quarterly Review.

Cheun, Samuel, Isabel von Koppen-Mertes and Benedict Weller (2009): The collateral frameworks of the Eurosystem, the Federal Reserve System and the Bank of England and the financial market turmoil. (107).

Curcuru, Stephanie E., Tomas Dvorak and Francis E. Warnock (2008): Cross-Border Returns Differentials. The Quarterly Journal of Economics, 123(4), pp. 1495-1530.

ECB (2002): The liquidity management of the ECB. ECB monthly bulletin, pp. 41-53.

ECB (2008): Changes in tender procedure and in the standing facilities corridor. Press Release, 8 October 2008.

ECB (2010): ECB decides on measures to address severe tensions in financial markets. Press Release, 10 May 2010.

ECB (2011): ECB announces measures to support bank lending and money market activity. Press Release, 8 December 2011.

ECB (2013a): Annex I, THE IMPLEMENTATION OF MONETARY POLICY IN THE EURO AREA. In: Official Journal of the European Union (ed.), GUIDELINE OF THE EUROPEAN CENTRAL BANK of 20 September 2011 on monetary policy instruments and procedures of the Eurosystem, vol. 9. Official Journal of the European Union.

ECB (2013b): Liquidity regulation and monetary policy implementation. ECB monthly bulletin, pp. 73-89.

ECB (2014): Recent developments in excess liquidity and money market rates. ECB monthly bulletin, pp. 69-82.

Ennis, Huberto M. and Todd Keister (2008): Understanding monetary policy implementation. Economic Quarterly, (Sum), pp. 235-263. 
Glocker, Christian and Pascal Towbin (2012): Reserve Requirements for Price and Financial Stability: When Are They Effective? International Journal of Central Banking, 8(1), pp. $65-114$.

Gonzalez-Paramo, Jose Manuel (2007): The challenges to liquidity management in the euro area: the perspective of the ECB. European Central Bank.

Gray, Simon (2011): Central Bank Balances and Reserve Requirements. IMF Working Papers 11/36, International Monetary Fund.

Handig, Martin, Robert Holzfeind and Clemens Jobst (2012): Understanding TARGET 2: The Eurosystem's Euro Payment System from an Economic and Balance Sheet Perspective. Monetary Policy $\mathcal{E}$ the Economy, (1), pp. 81-91.

Hauck, Achim and Ulrike Neyer (2010): The euro area interbank market and the liquidity management of the eurosystem in the financial crisis. DICE Discussion Papers, (09).

Natixis (2014): Zone euro: y a-t-il un risque de cliff de liquidité ? Flash économie N296.

Nautz, Dieter (1998): Banks' demand for reserves when future monetary policy is uncertain. Journal of Monetary Economics, 42(1), pp. 161-183.

Poole, William (1968): Commercial Bank Reserve Management In A Stochastic Model: Implications For Monetary Policy. Journal of Finance, 23(5), pp. 769-791.

Reuters (2012): European banks prepare for worst, hoard cash. US edition.

The Wall Street Journal (2013): Large European Banks Stash Cash. WSJ Europe.

Whelan, Karl (2014): TARGET2 and central bank balance sheets. Economic Policy, 29(77), pp. 79-137.

Whitesell, William (2006): Interest rate corridors and reserves. Journal of Monetary Economics, 53(6), pp. 1177-1195. 


\section{Appendix}

\section{Appendix I: The interbank rate movements and the yield curve}

Figure 6: The interbank rate movements and the yield curve

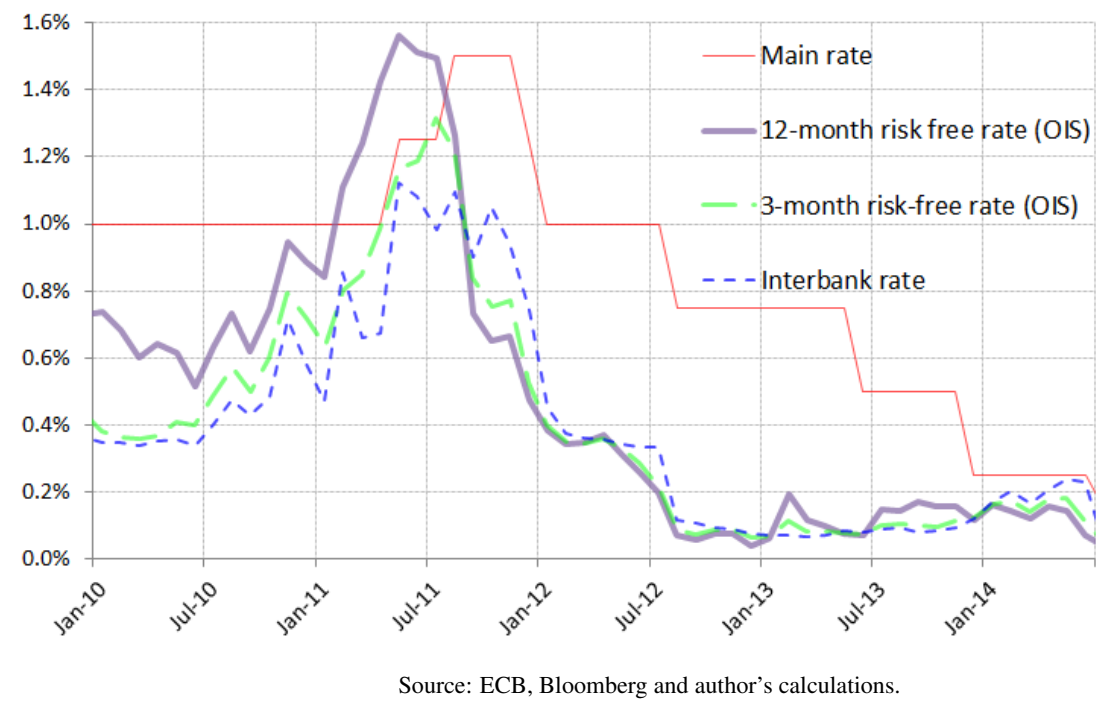

\section{Appendix II: Adding loans to the real Economy}

The goal of this appendix is to shown that the problem studied in this paper is independent of the provision of loans to the real economy made by banks. ${ }^{27}$

The assets of bank " $\mathrm{i}$ ", are the reserves held at the central bank " $R^{i}$ " and the amount of loans granted to non-bank agents, including holdings of securities issued by non-bank agents " $L$ " .

Liabilities of bank "i" are the net interbank borrowings $B^{i}$, borrowings from the central bank " $M$ " and the liability of bank "i" to the public (including its equity) " $d^{i}$ ".

"net deposits", $D^{i}$ can be defined as $D^{i}=d^{i}-L^{i}$. This item is of interest because it appears in the profit function of banks. It represents the liquidity surplus (resp. shortage) of a bank toward, non-bank agents.

In the absence of excess reserves, and of reserve requirements, this would mean that: $-D^{i}=$ $M^{i}+B^{i}$

Recall that the assets of the central bank are the assets purchased outright (" $O$ "), and the amount of loans provided to banks (" $M$ "). The liabilities are the amount of reserves (" $R$ ") and

\footnotetext{
${ }^{27}$ This appendix consider the implication of loans in terms of liquidity. However, it is likely that the ability of banks to expand loans is anyway limited in the short run by capital regulations.
} 
the currency in circulation (“C”). Using the fact that all assets must equal liabilities means that:

$$
L+R+M+O=d+M+R+C
$$

It implies that:

$$
O-C=D
$$

This shows that $\mathrm{D}$, which represent the net amount of deposits from the non-banking sector "net"of the loans made, is fixed and determined by the central bank as it can adjust the amount of outright purchases if it sees an increase in currency (which is completely determined by the demand of the public). The gross amounts of loans and deposits is not addressed in the model but it should have no impact on the liquidity position of the banking sector or on any item of interest in this model.

It can seem surprising that deposits are fixed. When a bank grants a loan, it credits the funds on the account of the borrower, which are usually held at the same bank. Therefore, a bank granting a loan usually gains the required deposits at the same time (no change in " $D$ "). If the funds are spent by the borrower and assuming the recipients of the funds have not an account with the bank originally granting the loan, the banks will see its net deposits go down (lower $D^{i}$ ). If the funds are withdrawn from the bank in exchange for currency, the central bank will need to provide the banking sector with more funds (increase in $M^{i}$ and $C^{i}$ ). If they are not exchanged for currency, it means that another bank " $\mathrm{j}$ ” will experience an inflow of funds (and thus an increase in " $D^{j}$ " and $R^{j}$ above required reserves). Hence, the aggregate amount of deposits does not change if the amount of currency does not change.

To the extent that the interbank market functions well, the bank that has suffered from an outflow will be able to recover this liquidity via the interbank market, given that at least another bank has a liquidity surplus.

In a symmetric equilibrium this would never happen and either borrowers deposits all the funds at the bank from which they borrow or they exchange it for currency.

What can have an effect on the equilibrium is asymmetry. This happens when $D^{i} \neq D^{j}$. In the case of a symmetric equilibrium, it had to be the case that all variables for a given banks were all equal to the average (since there is a mass one of banks, the average is equal to the sum): $D^{i}=D, M^{i}=M$ and $B^{i}=B=0$. However, it would be reasonable to assume that banks 
differ in the size if their net deposit base. It is still the case that, $-D^{i}=M^{i}+B^{i}$. One can assume that the central bank allocates an equal amount of loans to each bank. Then $-D^{i}=M+B^{i}$. Idiosyncratic changes (expected or unexpected) in $D^{i}$ can occur, if the interbank market remains competitive, this should not change anything to the interbank rate or liquidity that are the two main object of interest of this paper. ${ }^{28}$ This would just be a reallocation. For instance, a bank that is structurally taking more deposits than its peers $\left(D^{i}>D\right)$ would be a structural lender on the interbank market $\left(B^{i}<B\right)$. If it remunerates these deposits at the same rate as interbank loans, this should not be a first order change to profits either and would therefore not enter into the maximization problem of a risk-neutral bank.

The fact that the deposit bases are not symmetric really matters when the interbank market is unable to relocate efficiently liquidity. This case is already addressed in the paper when the banking sector is fragmented, it would be equivalent to: $D^{P}+F=D^{C}-F$.

Bianchi and Bigio (2014) assume that granting a loan (and taking the resulting deposit) increases liquidity risk (the probability of losing deposits). This case is beyond the scope of this paper, but it would not change the results, if the interbank market remains competitive in the core and if peripheral banks have unlimited access to central bank funding.

\section{Appendix III: Asymmetric corridor}

Let $r_{M}$ be anywhere between the interest rates of the two standing facilities:

$$
r_{M}=\alpha r_{r}+(1-\alpha) r_{X}
$$

Where $1 \geq \alpha \geq 0$. Then, (12) can be rewritten:

$$
R^{c b}=K+G^{-1}(\alpha)
$$

Excess liquidity is given by:

$$
R-K=G^{-1}(\alpha)
$$

It is strictly positive whenever the main rate is strictly closer from the deposit facility rate

\footnotetext{
${ }^{28}$ Several papers address the case where large lenders/borrowers of funds have market power in the interbank market, for instance Bech and Klee (2011) or Afonso and Lagos (2015). Such frictions would not change the results of the present paper.
} 
than the marginal lending facility rate $(\alpha>0.5)$.

Since its creation, the ECB has left its main interest rate most of the time in the middle of the corridor $(\alpha=0.5)$. In this case, assuming that $G($.$) is the cumulative distribution function of$ a symmetric distribution around zero, excess liquidity should be zero. However, from November 2013 to June 2014 the corridor was asymmetric, with $r_{r}=0, r_{M}=0.25 \%$ and $r_{X}=0.75 \%$. (40) implies that during this period the ECB triggered some excess liquidity because of its asymmetric corridor. This phenomenon is independent of fragmentation.

Proposition 5: In a fixed-rate full allotment regime, an asymmetric corridor can trigger excess liquidity. This excess liquidity cannot be sterilized.

\section{Appendix IV: International Investment Positions and Fragmentation}

If a well-integrated monetary union becomes suddenly fragmented, deficit countries will not be able to roll-over their loans from core banks. It means that once the loans arrive at maturity, peripheral banks have to pay them off, i.e. they have to send a certain amount of liquidity ("F") back to core banks. The only way for the loans to be paid-off in the absence of other sources of financing would be for deficit countries to manage a current account surplus (by macroeconomic identity). As this is not possible overnight, the banks will need to obtain the liquidity to repay core banks in some other way. Deficit countries' banks borrow from the central bank to repay surplus countries' banks. The fact that the interbank market became inaccessible for peripheral banks at a time when they had a large net liability toward core banks is further documented in this appendix. Figures 7 and 8 below display the net International Investment Position (IIP) of core and peripheral countries. Each category of financial flow (direct investment, portfolios investment, etc.) is netted. A negative position represents a liability and is equivalent to past inflows. 
Figure 7: IIP of TARGET2 surplus countries (Germany, Netherlands, Luxembourg and Finland), broken down by category (EUR bn).

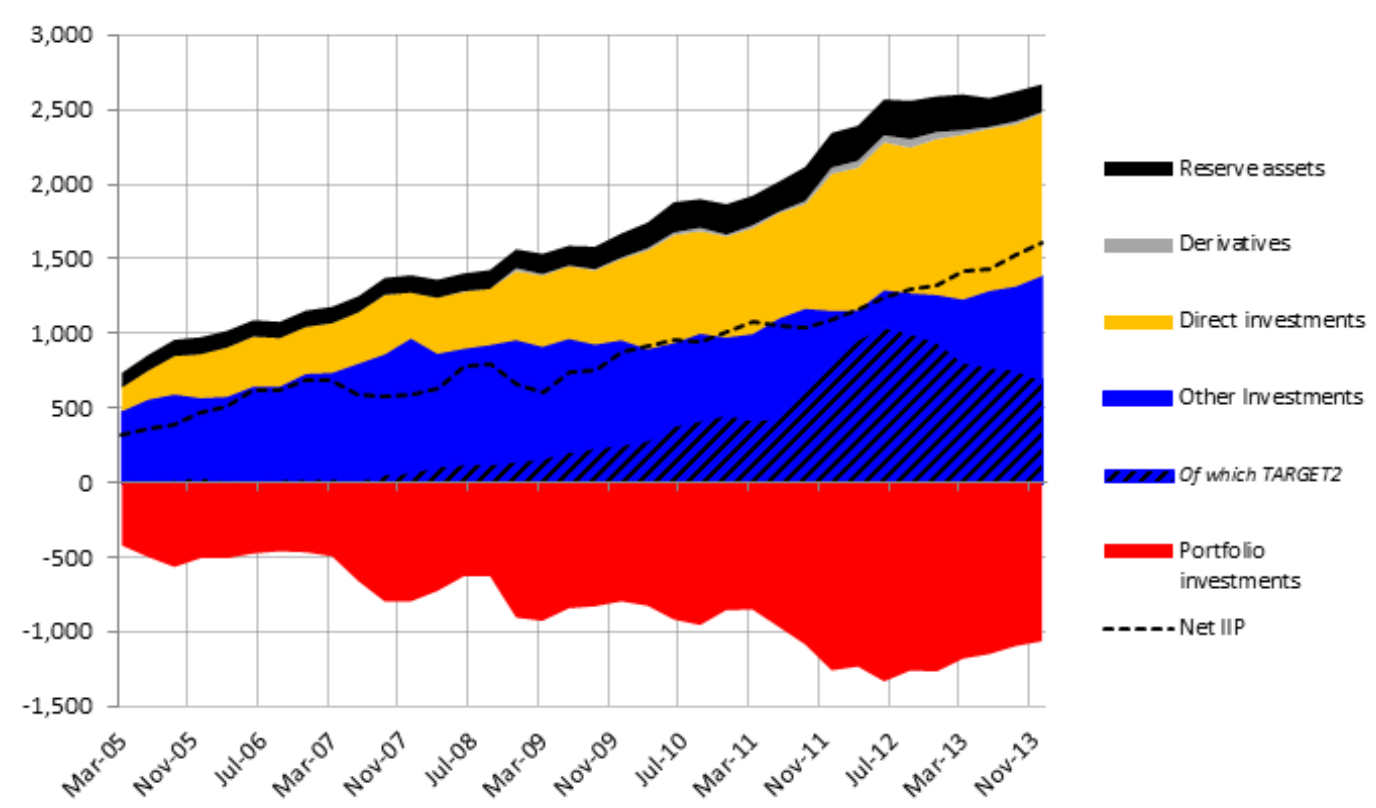

Source: IMF BOPS, "Euro crisis monitor" and author's calculations.

Figure 8: IIP of TARGET2 deficit countries (Portugal, Italy, Greece and Spain), broken down by category (EUR bn).

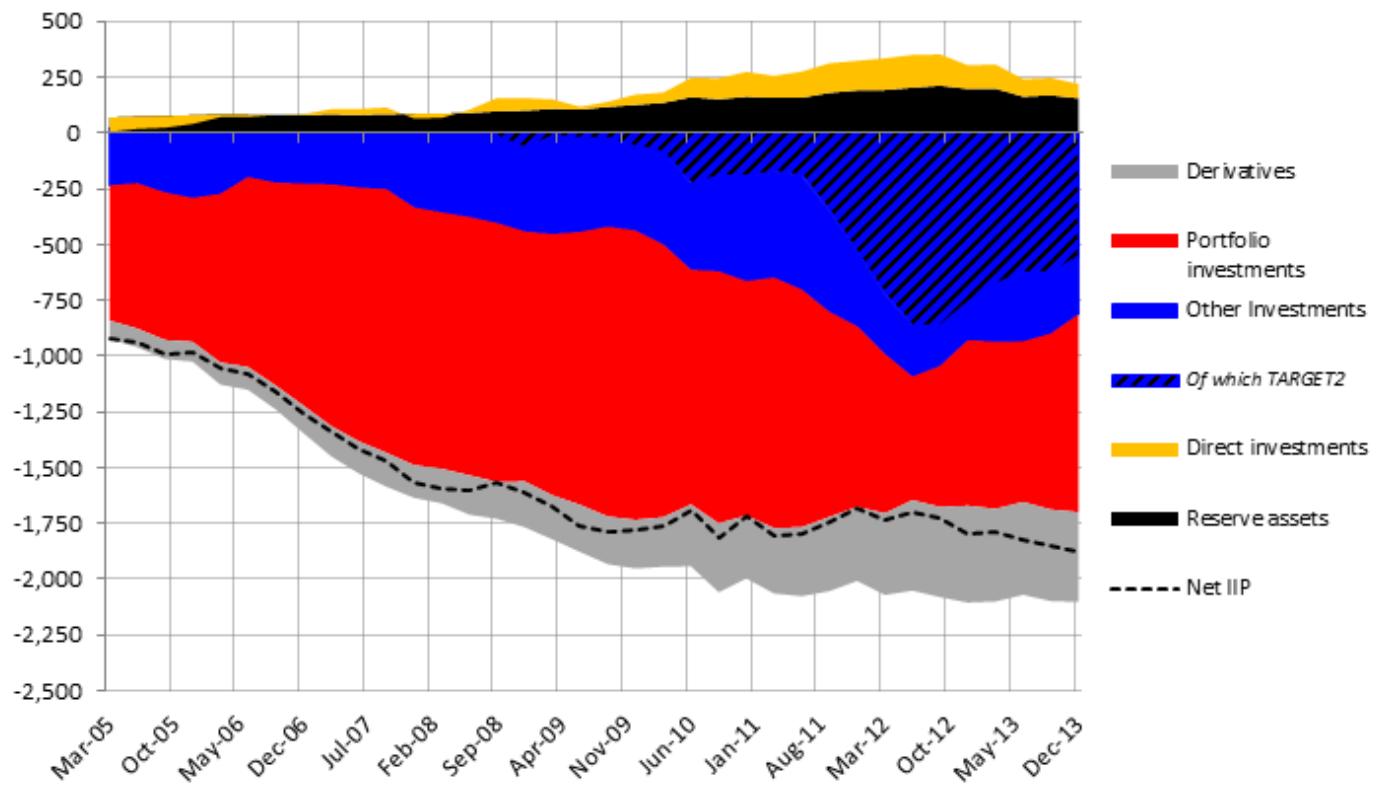

Note:Ireland is excluded due data unavailability.

Source: IMF BOPS, "Euro crisis monitor" and author's calculations. 
It shows that indeed core countries (Germany, Netherlands, Luxembourg and Finland) had a substantial net creditor position (positive net IIP) toward the rest of the world. Except for portfolios investment, they have a creditor position in all types of investments. Peripheral countries (Portugal, Italy, Greece and Spain) on the other hand had accumulated a net external liability before the outbreak of the crisis. This is the result of past accumulated current account imbalances. Interbank loans appear in the category "other investments". 29 "Other investments" from core banks indeed, seem to have stopped with the crisis (Graph 1). Most of the money lent abroad by banks before the crisis seems to have been switched to deposit accounts at the central bank, as suggested by the substantial increase of TARGET2 imbalances, which is also classified as "other investments". ${ }^{30}$ Looking at interbank loan volumes (not displayed here), also suggest that core-periphery interbank loans dried up, in the wake of the crisis.

In both core and periphery, net "other investments" excluding TARGET2 balances almost completely vanished (Figures 7 and 8). Portfolio investments also probably played a role in the capital reversal between core and periphery. Indeed, TARGET2 deficits rose in the periphery also at the expense of its portfolio investments liability. As a mirror image, the TARGET2 surplus of core countries seems to be related to the decrease of "other investments" positions but also to the increase of the liability in portfolios investments. This should not come as a complete surprise, since short term bank securities and interbank borrowings are close substitutes. The former appears in "portfolio investment" and the latter in "other investments". 31 Still "other investments" seems to have played a larger role.

Recall that a TARGET2 liability means that there is more money transferred out of the country than in the country. This is a sign per se that banks have difficulties to attract liquidity below the central bank rate (i.e. it shows fragmentation). The total international investment liability position of a country gives the limit to how much TARGET2 liabilities can rise.

\footnotetext{
${ }^{29}$ See IMF Balance of payments manual 6.

${ }^{30}$ Similar conclusions are reached by Auer (2014) using accumulated current account and financial flows. This appendix rather uses international investment positions, because the relevant concept is the total liability positions and not recent borrowings. Moreover, IIP statistics offer some advantages over international flow figures (see for instance Curcuru et al. (2008) for the US case).

${ }^{31}$ Theoretically, the stock of borrowings that makes up F, can be direct interbank borrowings (e.g. borrowings of Alpha bank from Deutsche bank) or indirect (e.g. a German savers investing its money into a British pension fund, which in turns invests in the Greek corporate bond market). The only relevant aspect is that as the crisis breaks, the peripheral banking system suffers from withdrawals of private capital in Euros, while the core banks experience a net capital inflow (also in Euros). These flows create a liquidity shortage for the Greek banking system and a surplus for the German banking system whether in come in forms of loans, deposits or securities. The counterparties do not matter as non-bank agents have anyway to store their liquidity with their banks, which in turn store it at the central bank.
} 


\section{Appendix V: Graphical representation of the demand for liquidity at the central bank}

Diagram 3 below is a graphical representation of the theoretical mechanism described in the paper. When $\mathrm{F}$ is small, peripheral and core banks ask just enough liquidity to fulfill their liquidity needs (reserve requirements, etc.). As F increases peripheral banks ask more and more liquidity, and if $\mathrm{F}$ is small (below the critical level $K^{C}+C^{C}-O^{C}$ ) core banks ask less and less. At some point (when $\mathrm{F}$ is higher than the critical level) core banks ask zero to the central bank and the increase in F triggers excess liquidity because the increase in the demand of peripheral banks (vertical distance between the zero line and the upward slopping line) is not matched by a decrease in the demand by core banks.

Diagram 3: The demand of refinancing of core and peripheral banks.

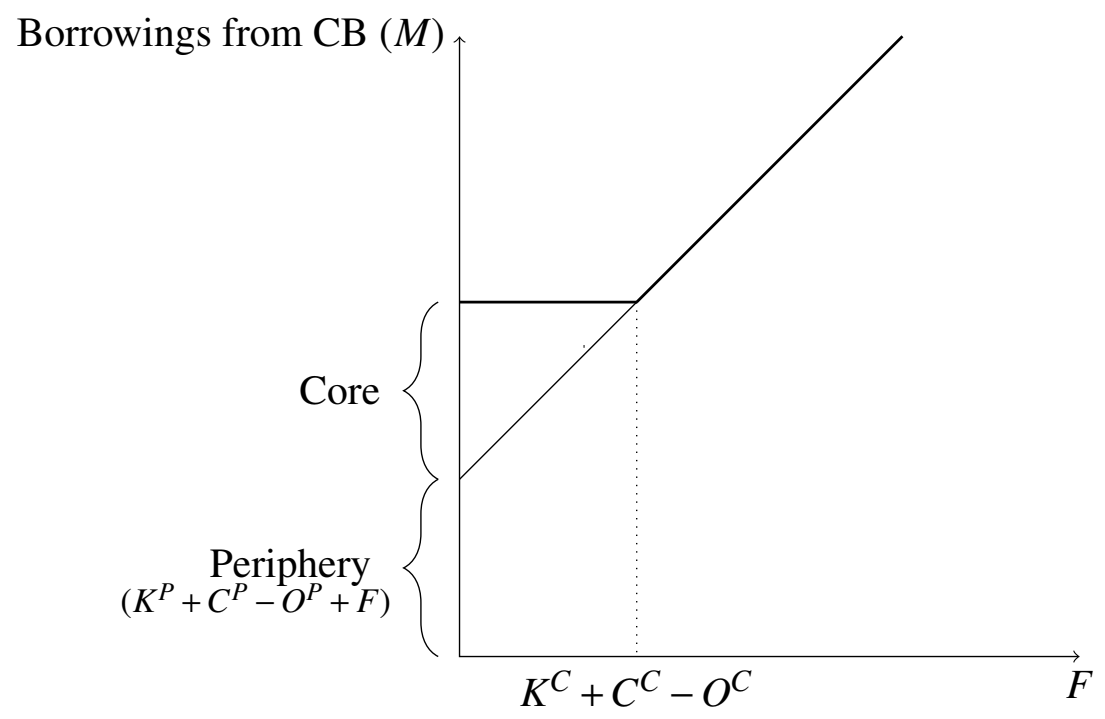

\section{Appendix VI: Underbidding at sterilization operations}

If the sterilization operations are too large but fragmentation is large enough, such that core banks borrow nothing from the central bank (case where $K^{C}-O^{C}+C^{C}<F<K^{C}-O^{C}+$ $C^{C}+\underline{S}$ ), there will be "underbidding". Underbidding is defined as the situation were banks deposit/demand less liquidity than what the central bank demands/offers, for instance, at sterilization operations. Core banks will only deposit up to: $S=F-\left(K^{C}-O^{C}+C^{C}\right)$. This brings excess liquidity close to zero and the interbank rate close to the main interest rate. In essence, core banks just deposit their surplus of liquidity (the difference between $\mathrm{F}$ and their liquidity 
needs) and keep the rest to satisfy their liquidity needs. Underbidding is the difference between the amount the central bank intends to absorb, $\underline{S}$ and the amount actually absorbed $S$. The model therefore suggests that there will be underbidding as fragmentation decreases and the interbank rate approaches the main rate.

\section{Appendix VII: TARGET2 technical appendix}

There are two things that differentiate F from TARGET2 imbalances.

First, some capital movements from one country to the other are not recorded in TARGET2. Indeed some capital movements can occur through the use of banknotes. Such movements can be substantial and turn countries with apparent deposit flight into capital recipients (see Handig et al. (2012)).

Also, there are some transactions in the TARGET2 payment system that do not correspond to capital movements. This second point has not been noted in the literature. For instance, the use of swap lines with foreign central banks triggers accounting transactions between central banks and will appear in TARGET2 while actually not a euro has moved within the monetary union. The Eurosystem lent US Dollars to its banks during the crisis. In order to finance such loans, it has made swaps with the Fed, swapping Dollars against Euros. The ECB was receiving the Dollars while it was national central banks lending Dollars to their banks. Therefore, the ECB lent Dollars to national central banks against a TARGET2 claim. National central banks would then see a TARGET2 liability appear on their balance sheets. This probably deteriorated the TARGET2 position of some national central banks during the crisis, in particular those that extensively lent Dollars to their banks. Ideally, one should correct for these two data issues before using TARGET2 imbalances. Unfortunately, the data series needed to make such adjustment are not publicly available. 


\section{Appendix VIII: Liquidity absorbing operations in the Euro-Area between 2010 and 2014}

Figure 9 plots the interbank rate and the average rate at which the Eurosystem was able to absorb liquidity between 2010 and 2014 .

Figure 9: EONIA vs sterilization rate (Maintenance period average, percentage points)

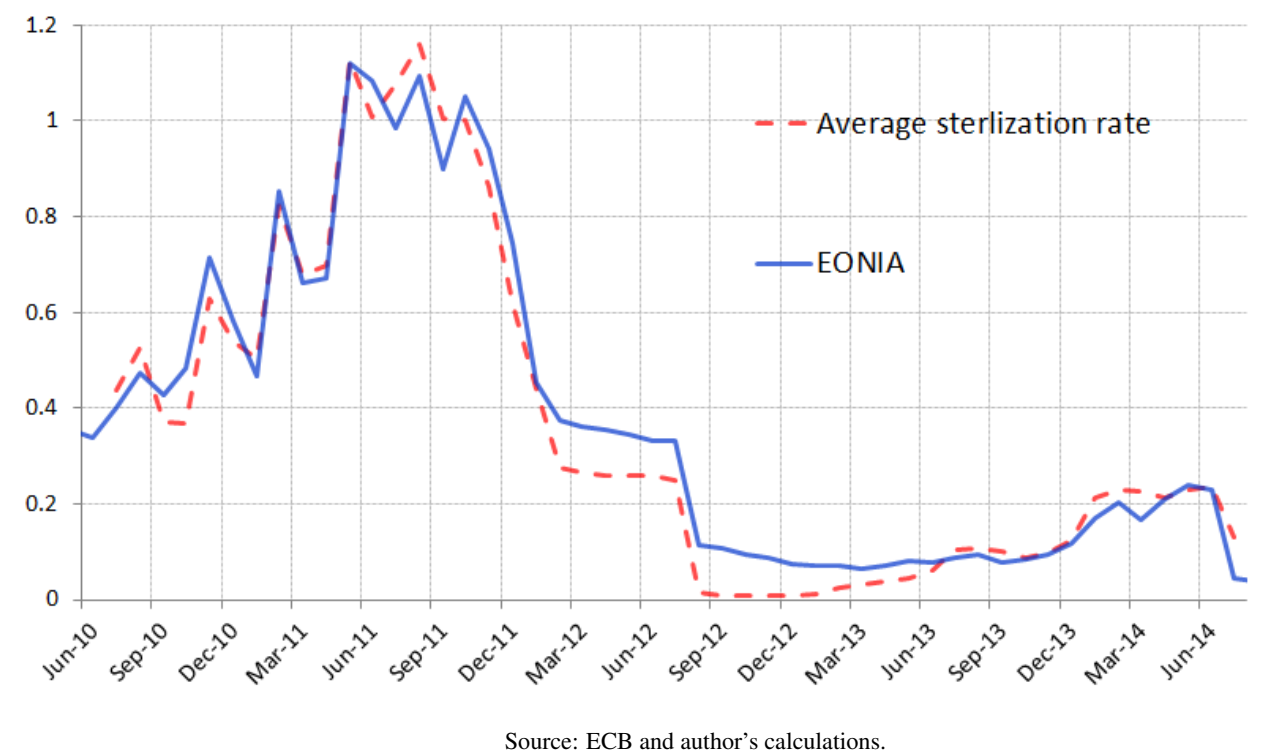

There are wedges between the two rates at several points in time. This can come from the fact that some banks that are safe enough to participate to the EONIA interbank market have to pay a risk premium when they borrow, while in the model it is assumed that all banks participating to the interbank market were perceived risk-less. 